\title{
A Subpopulation of Neurochemically-Identified Ventral Tegmental Area Dopamine Neurons Is Excited by Intravenous Cocaine
}

\author{
Carlos A. Mejias-Aponte, ${ }^{1}$ Changquan Ye, ${ }^{1}$ Antonello Bonci, ${ }^{2,4}$ Eugene A. Kiyatkin, ${ }^{3}$ and Marisela Morales ${ }^{1}$ \\ ${ }^{1}$ Integrative Neuroscience Research Branch, Neuronal Networks Section, ${ }^{2}$ Cellular Neurobiology Research Branch, Synaptic Physiology Section, and \\ ${ }^{3}$ Behavioral Neuroscience Research Branch, Behavioral Neuroscience Section, In Vivo Electrophysiology Unit, Intramural Research Program, National \\ Institute of Drug Abuse, Baltimore, Maryland 21224, and ${ }^{4}$ Solomon H. Snyder Department of Neuroscience, Johns Hopkins University School of Medicine, \\ Baltimore, Maryland 21205
}

\begin{abstract}
Systemic administration of cocaine is thought to decrease the firing rates of ventral tegmental area (VTA) dopamine (DA) neurons. However, this view is based on categorizations of recorded neurons as DA neurons using preselected electrophysiological characteristics lacking neurochemical confirmation. Without applying cellular preselection, we recorded the impulse activity of VTA neurons in response to cocaine administration in anesthetized adult rats. The phenotype of recorded neurons was determined by their juxtacellular labeling and immunohistochemical detection of tyrosine hydroxylase (TH), a DA marker. We found that intravenous cocaine altered firing rates in the majority of recorded VTA neurons. Within the cocaine-responsive neurons, half of the population was excited and the other half was inhibited. Both populations had similar discharge rates and firing regularities, and most neurons did not exhibit changes in burst firing. Inhibited neurons were more abundant in the posterior VTA, whereas excited neurons were distributed evenly throughout the VTA. Cocaine-excited neurons were more likely to be excited by footshock. Within the subpopulation of TH-positive neurons, $36 \%$ were excited by cocaine and $64 \%$ were inhibited. Within the subpopulation of TH-negative neurons, $44 \%$ were excited and $28 \%$ were inhibited. Contrary to the prevailing view that all DA neurons are inhibited by cocaine, we found a subset of confirmed VTA DA neurons that is excited by systemic administration of cocaine. We provide evidence indicating that DA neurons are heterogeneous in their response to cocaine and that VTA non-DA neurons play an active role in processing systemic cocaine.
\end{abstract}

Key words: cocaine; in-vivo electrophysiology; intravenous; juxtacellular; single unit; ventral tegmental area

\section{Introduction}

Cocaine exerts its rewarding effects, in part, by modulating the activity of neurons within the ventral tegmental area (VTA; Zweifel et al., 2008; Sombers et al., 2009). Intravenous cocaine produces either inhibition or excitation of VTA neurons (Einhorn et al., 1988; Steffensen et al., 2008; Koulchitsky et al., 2012; MejíasAponte and Kiyatkin, 2012). It has been postulated that VTA dopamine (DA) neurons are inhibited by intravenous cocaine. This suggestion is based on indirect identification of DA neurons by relaying on the electrophysiological characteristic of longduration action potentials and slow discharge rates (Einhorn et al., 1988; Hinerth et al., 2000). However, some VTA DA and

\footnotetext{
Received Aug. 8, 2013; revised Dec. 3, 2014; accepted Dec. 10, 2014.

Author contributions: M.M., C.A.M.-A., E.A.K., and A.B. designed research; M.M. and C.A.M.-A. performed research; M.M., C.A.M.-A., C.Y., and E.A.K. analyzed data; M.M. and C.A.M.-A. wrote the paper.

This work was supported by the National Institute on Drug Abuse Intramural Research Program. We thank Robert Ator for his help in surgeries, Jean Pieper for histology processing, and Drs. Lindsay De Biase, Alexxai Kravitz, Jana Mejia-Tobier, Meriem Gaval Cruz, David Barker, and David Root for their helpful comments on this manuscript.

The authors declare no competing financial interests.

Correspondence should be addressed to Marisela Morales, Integrative Neuroscience Research Branch, Neuronal Networks Section, Intramural Research Program, National Institute of Drug Abuse, Biomedical Research Center, Suite 200, 251 Bayview Boulevard, Baltimore, MD 21224. E-mail: mmorales@nih.gov.

DOI:10.1523/JNEUROSCI.3422-13.2015

Copyright $\odot 2015$ the authors $\quad 0270-6474 / 15 / 351965-14 \$ 15.00 / 0$
}

non-DA neurons share similar electrophysiological characteristics; thus, electrophysiological identification alone is insufficient to determine the phenotype of VTA neurons (Kiyatkin and Rebec, 1998; Ungless et al., 2004; Margolis et al., 2006; Luo et al., 2008; Cohen et al., 2012; Li et al., 2012).

VTA non-DA neurons are either glutamate or GABA and, like DA neurons, are part of the mesocorticolimbic pathway (Carr and Sesack, 2000; Yamaguchi et al., 2007, 2011; Margolis et al., 2012; Morales and Root, 2014). Some VTA non-DA neurons make synapses on DA neurons and can locally regulate their output (Omelchenko and Sesack, 2009; Dobi et al., 2010; Tan et al., 2012; van Zessen et al., 2012). Therefore, elucidating the effects of cocaine on both DA and non-DA neurons are essential to have a better understanding on the role of VTA in the neurobiology of cocaine addiction. In this regard, recent electrophysiological studies have shown that cocaine excites a subset of VTA neurons characterized by short-duration action potentials and fast discharge rates (Steffensen et al., 2008), two electrophysiological properties associated with VTA GABA neurons (Maeda and Mogenson, 1980; Steffensen et al., 1998). However, electrophysiological analysis of optogenetically identified VTA GABA neurons has shown that, similar to VTA DA neurons, some VTA GABA neurons exhibit slow discharge rates (Tan et al., 2012). 
To study the effects of systemic administration of cocaine on identified VTA DA and non-DA neurons, we labeled and phenotyped VTA neurons after their responses to intravenous cocaine administration were recorded. Neurons were recorded under urethane anesthesia without using electrophysiological preselected criteria. To determine the DA or non-DA phenotype of cocaine-responsive neurons, we combined in vivo juxtacellular labeling of the recorded neurons and with subsequent immunolabeling with antibodies against tyrosine hydroxylase (TH), a marker for DA neurons. We found populations of neurochemically identified DA and non-DA neurons that were either excited or inhibited after intravenous cocaine. Among DA neurons, onethird were excited by intravenous cocaine, demonstrating that a substantial portion of DA neurons are excited by cocaine.

\section{Materials and Methods}

Ninety-four male Long-Evans rats (360-500 g; Charles River Laboratories) were used in these experiments. Rats were housed in pairs until the day of surgery and individually thereafter. All subjects were maintained on a $12 \mathrm{~h} \mathrm{light/dark} \mathrm{cycle} \mathrm{with} \mathrm{access} \mathrm{to} \mathrm{food} \mathrm{and} \mathrm{water} \mathrm{ad} \mathrm{libitum.} \mathrm{The}$ experimental procedures followed the Principles of Laboratory Animal Care published by the National Institutes of Health (Publication 86-23, 1996) and were approved by the Animal Care and Use Committee of the National Institute on Drug Abuse Intramural Research Program. Experimental protocols were designed to minimize the number of animals and to reduce pain and discomfort to experimental subjects.

Intravenous catheterization and placement of the electrodes

Each rat was anesthetized with a mixture of sodium pentobarbital (32.5 $\mathrm{mg} / \mathrm{kg})$ and chloral hydrate $(145 \mathrm{mg} / \mathrm{kg})$ delivered intraperitoneally. Each rat was mounted in a stereotaxic frame. Two screws, each one soldered to a wire, were threaded in the frontal bone for encephalographic recordings; one over the prefrontal cortex (PFC), $0.8 \mathrm{~mm}$ mediolateral and $3.0 \mathrm{~mm}$ anteroposterior from bregma; and a ground electrode, $0.8 \mathrm{~mm}$ mediolateral and $6.0 \mathrm{~mm}$ anteroposterior from bregma. The screws in the frontal bone were covered, and their wires were secured with dental acrylic, keeping their pin connectors exposed. Another screw was placed in the right parietal bone to serve as a reference electrode for single-unit recordings and to secure an intravenous catheter and wires placed subcutaneously to monitor heart activity. The base of the screw in the parietal bone was covered with dental acrylic keeping bregma and lambda and the central suture visible as stereotaxic landmarks for use on the day of electrophysiological recordings.

For electrocardiogram (ECG) recordings, two $127 \mu \mathrm{m}$ perfluoroalkoxy-insulated stainless steel wires (A-M Systems) were routed subcutaneously in the chest. The insulation of the wires was removed at each end. One wire was placed in the lower chest close to the left ventricle, and the other wire was placed in the upper chest above the left atrium. Both wires were routed subcutaneously around the back of the neck and exited at the surgical area of the head. The end of each wire was soldered to gold male pins and glued to the skull over the right parietal bone.

For drug administration, a SILASTIC catheter (inner diameter of 0.51 $\mathrm{mm}$, outer diameter of $0.94 \mathrm{~mm}$; Dow Corning) was placed in the external right jugular vein. The catheter was routed subcutaneously around the back of the neck and exited at the surgical area of the head. The end of the catheter was slipped over a bent and blunted 23-gauge syringe hub, which was secured next to the parietal lobe screw with dental acrylic. To keep the catheter patent, $0.2 \mathrm{ml}$ of a $0.9 \%$ saline solution was flushed through the catheter every day after surgery.

Surgeries were performed 3-10 d before electrophysiological recordings to (1) reduce the pain or trauma cause during catheter implantation on the recording day, (2) allow more time for recordings, and (3) match the experimental protocol of previous experiments in awake rats conducted in our laboratory.

\section{Single-unit, ECG and EEG recordings}

On the day of electrophysiological recordings, each rat was anesthetized with urethane $(1.4 \mathrm{~g} / \mathrm{kg}$, i.p. ) and mounted in a stereotaxic frame. Anes- thesia was supplemented as needed by giving intraperitoneal boosters of $0.14 \mathrm{~g} / \mathrm{kg}$ urethane. A hole was then drilled in the parietal bone to access the VTA using stereotaxic coordinates. Glass micropipettes (6-18 M $\Omega$ ) filled with $4.0 \%$ Neurobiotin (Vector Laboratories) dissolved in $0.5 \mathrm{M}$ potassium acetate were used for recording and juxtacellular labeling. Neuronal activity was amplified and filtered using three amplifiers in series: (1) a Neuro Data IR283A (Cygnus Technology); (2) a Grass P15 (Astro-Med); and (3) Neurolog System (Digitimer). Single-neuron action potentials were bandpass filtered between 300 and $3000 \mathrm{~Hz}$. Electroencephalogram (EEG) electrodes were connected to a Grass P511 (Astro-Med) amplifier, amplified, and filtered in a 1-100 Hz bandwidth. ECG wires were connected to a Brownlee Precision 440 amplifier, amplified, and filtered in a 1-100 Hz bandwidth. All biopotentials were digitized using a Micro 1401 MK 2 Analog-Digital Converter (Cambridge Electronic Design) and stored on a computer using Spike 2 version 5.15 software (Cambridge Electronic Design).

VTA recordings were obtained from each animal using a sampling grid that extended $0.0-1.4 \mathrm{~mm}$ from midline, $7.0-9.0 \mathrm{~mm}$ from the brain surface, and 4.7-6.0 $\mathrm{mm}$ caudal to bregma. To avoid recording from substantia nigra neurons, the electrode was lowered at a $10^{\circ}$ angle. Our recordings were performed between two physiologically defined boundaries that delineate the VTA. The dorsal limit was defined by the detection of pre-rubral, rubral, and para-rubral neurons with short-duration action potentials and fast discharge rates, whereas the ventral boundary was defined by the detection of neurons with short-duration action potentials and brief interspike intervals that are indicative of interpeduncular nucleus neurons. Neuronal activity was recorded for $5 \mathrm{~min}$ to establish baseline and for 5 min after drug infusion before attempting juxtacellular labeling. Five to seven neurons were typically recorded per animal.

The dose of cocaine- $\mathrm{HCl}(0.25 \mathrm{mg} / \mathrm{kg})$ was chosen because it reinforces self-administration, evokes cortical EEG desynchronization, and induces a reliable rise in extracellular DA concentrations in the nucleus accumbens and frontal cortex (Carroll and Lac, 1997; Tanda et al., 1997; Wee et al., 2007; Kiyatkin and Smirnov, 2010). Moreover, this cocaine dose is low enough to permit multiple injections in the same recording session. Cocaine injections in the same animal were made at least $45 \mathrm{~min}$ apart to permit catabolism of the drug before the next infusion. This interval is four times the half-life of cocaine (Booze et al., 1997). Cocaine$\mathrm{HCl}$ was obtained from the National Institute on Drug Abuse.

\section{Juxtacellular labeling}

Five minutes after each intravenous cocaine injection, current pulses of 1-10 nA were delivered through the recording pipette in a $250 \mathrm{~ms}$ on, 250 ms off cycle using the Neuro Data IR283A (Cygnus Technology). The current was monitored and increased to produce and maintain entrainment of the activity of the neuron, yielding a higher number of spikes on the current on periods compared with the off periods. Cells were entrained between 2 and 15 min.

\section{Footpad stimulation}

Electrical pulses of $0.5 \mathrm{~ms}, 10 \mathrm{~mA}$ every $2 \mathrm{~s}$ were administered through a pair of stainless steel needles implanted subcutaneously in the surface of the contralateral rear footpad. Peristimulus time histograms were constructed at a $50 \mathrm{~ms}$ resolution and were used to determine excitatory and inhibitory epochs. A baseline period of $500 \mathrm{~ms}$ preceding stimulation was used to establish spontaneous discharge rate of each neuron. The onset of excitation was defined as the first bin whose value exceeded the mean baseline activity by 2 SDs when averaged with the following three bins. Response offset of excitation was determined as the time at which activity had returned to be consistent within 2 SDs of baseline. The onset of inhibition was defined as the first bin whose value was below the mean baseline activity by $35 \%$ when averaged with the following three bins. Response offset of excitation was determined as the time at which activity had returned to be consistently within $35 \%$ of baseline. The inhibitory or excitatory response magnitude was calculated using the following formula: (counts in inhibitory or excitatory epoch) - (mean counts per baseline bin $\times$ number of bins in the inhibitory or excitatory epoch). 


\section{VTA firing periodicity and EEG slow activity analyses}

PFC EEG and time of action potential of VTA neurons were imported to MATLAB (MathWorks) using the sigTOOL Neuroscience Toolkit for data collected using Spike2 (Cambridge Electronic Design). Firing periodicity of each VTA neuron was established using fast Fourier transform of the firing rate calculated within $50 \mathrm{~ms}$ bins, tapered with a hamming window on trace segments of 256 points ( $12.8 \mathrm{~s}$ ) with a $50 \%$ overlap, yielding a spectral resolution of $0.078 \mathrm{~Hz}$. PFC EEG was downsampled to $20 \mathrm{~Hz}$, and its spectral frequencies were calculated using fast Fourier transforms as described above. The power of each frequency was expressed as percentage of total power.

Correlation between VTA spiking activity and PFC EEG was determined by establishing the coherence of the cross-spectral density between the two recordings. The coherence squared correlation coefficient, $r^{2}$, was calculated from the squared cross-spectral density divided by the product of the spectral density of each recording. Coherence $r^{2}$ ranges from 0 to 1 , and the association of two signals is highest the closer $r^{2}$ is to 1. The two signals were considered significantly correlated when $r^{2}$ was higher than $95 \%$ confidence level. The confidence level was calculated as

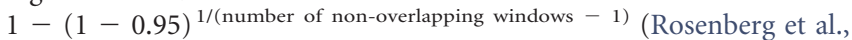
1989). On neurons that exhibited significant coherences, the phase between the firing activity of VTA neurons and PFC EEG was established by determining the phase lag angle at the frequencies showing significant coherence. The phase lag angle was divided by $2 \pi$ to obtain a cycle ranging from -0.5 to 0.5 . A phase lag of 0 indicated in-phase, a negative phase value indicated that the firing activity of VTA neurons preceded PFC EEG, and a positive phase value indicated that firing activity followed the PFC EEG.

\section{Neurobiotin and TH immunostaining}

At the end of the experimental session, each animal was transcardially perfused with $100 \mathrm{ml}$ of $0.9 \%$ saline at a rate of $2 \mathrm{ml} / \mathrm{s}$, followed by $350 \mathrm{ml}$ of $4 \%$ paraformaldehyde at a rate of $2 \mathrm{ml} / \mathrm{s}$ during the first minute and the remainder of the solution at $1 \mathrm{ml} / \mathrm{s}$. The brains were removed and kept in $4 \%$ paraformaldehyde overnight. Brains were transferred to $18 \%$ sucrose in $0.1 \mathrm{~m}$ phosphate buffer $(\mathrm{PB})$ and allowed sufficient time to sink to the bottom of the container to ensure the sucrose was exchanged for the paraformaldehyde, usually overnight. The sucrose was decanted and replaced by fresh $18 \%$ sucrose overnight. Brains were frozen in dry ice and kept frozen at $-80^{\circ} \mathrm{C}$ until sectioned.

Coronal $20 \mu \mathrm{m}$ sections of the VTA were obtained and collected in $0.1 \mathrm{M}$ PB. The sections were washed six times with $\mathrm{PB}, 2$ min each time, before being placed in Alexa Flour 488 streptavidin-conjugated antibody (1:400; Life Technologies) and anti-mouse TH antibody (1:1000) in $0.3 \%$ Triton X-100 in PB $(0.3 \%$ PBT $)$ and incubated at $4^{\circ} \mathrm{C}$ overnight. Sections were washed six times with PBT before being incubated for $2 \mathrm{~h}$ with Alexa Flour 594 donkey anti-mouse (Life Technologies). Sections were washed four times in PBT and twice in PB. Sections were mounted in slides, coverslipped, and photographed.

The location of VTA neurons was identified using two strategies. Some VTA neurons were juxtacellularly labeled, and their localization was confirmed histologically. The location of the others neurons was determined by the recording tracts and stereotaxic position relative to a juxtacellularly labeled VTA neuron.

\section{Data analysis}

Single-neuron responses. We analyzed changes in spontaneous activity as we reported previously (Mejías-Aponte and Kiyatkin, 2012). In brief, activity was analyzed by averaging 101 -s segments of impulse activity in a sliding window moving in $1 \mathrm{~s}$ steps. This averaging window filters sudden changes in rate and focuses the analysis on tonic long-lasting changes. Responses to cocaine were defined as changes in firing rate $20 \%$ above or below the spontaneous activity for at least $30 \mathrm{~s}$. The onset of response was the first bin within the $10 \mathrm{~s}$ averaging window above or below $20 \%$ of the spontaneous activity in the predrug period.

Population response. Impulse activity from individual neurons was summed every $5 \mathrm{~s}, 1 \mathrm{~min}$ before and $5 \mathrm{~min}$ after the initiation of drug infusion. $\mathrm{Z}$ scores were computed using the mean $\pm \mathrm{SD}$ of the discharge rate within the minute of predrug activity. The onset and duration of cocaine-evoked population responses were determined by analyzing the $\mathrm{SD}$ of the discharge rate. The SD was used for the detection of changes in discharge rate independent of their direction.

Firing regularity. Three measures of firing regularity were determined. The coefficient of variation (CV) was calculated by dividing the SD by the mean of the interspike interval. Because the CV cannot distinguish irregularities attributable to an increase in burst firing or a pause in firing, we also determined the coefficient of variation 2 (CV2), the average of the $\mathrm{SD}$ of two adjacent spikes, divided by their means, and multiplied by square root of 2 (Holt et al., 1996). A higher CV2 reflects increase firing variability attributable to burst firing. We also determined the Fano factor, the variance divided by the mean of distribution of the density discharge histogram (Kaneoke and Vitek, 1996).

Spikes in burst. The most common parameters to quantify burst firing in putative DA neurons consists of identifying the action potentials occurring $<80 \mathrm{~ms}$ apart ( $12.5 \mathrm{~Hz}$ instant rate) and set these as the onset of a burst and twice this interval, $160 \mathrm{~ms}$, as the offset of a burst (Grace and Bunney, 1984). However, when a neuron fires fast $(>10 \mathrm{~Hz})$, many of its spikes may occur in $<80 \mathrm{~ms}$ without the neuron being in burst firing. Therefore, to determine onset and offset of burst firing on a given neuron, we used the density discharge histogram method (Kaneoke and Vitek, 1996). In brief, the recordings were segmented in intervals of the size of the mean interspike interval, and the number of spikes in each interval was counted. The counts were used to construct a density discharge histogram, and a burst threshold was determined based on the shape of the histogram. When the density discharge histogram had a bimodal distribution with a clear break, the mean interspike interval was divided by the number of the bin in the break point of the density discharge histogram. This number was used as the onset of burst firing and twice this number as the offset of a burst. When the density discharge histogram did not have a bimodal distribution but exhibited a sudden positive change in the slope, the bin in which the sudden change occurred was used as the breaking point. When the density discharge histogram followed an exponential decay, the breaking point was the steepest inflection in the decay. After determining the burst onset and offset of a given neuron, the burst of the neuron was detected using the burst script in Spike2. Both predrug and postdrug activities were analyzed. Within the postdrug period, we analyzed data from 120 to $300 \mathrm{~s}$ after the initiation of the drug infusion. For each neuron, the onset and offset of the burst were determined for the predrug and postdrug periods. The density discharge method allowed determination of a breaking point for each neuron; neurons with burst onset $<5 \mathrm{~Hz}$ were categorized as neurons lacking burst activity.

Statistics. Parametric statistics were used after verifying compliance for normal distribution and equal variance assumptions. One-way and twoway ANOVA were used to compare between-group effects. Repeatedmeasures ANOVAs were used to compare within-group effects across time. Normality was assessed using the D'Agostino and Pearson omnibus normality test. Equality of variance was assessed with the Bartlett's test for equal variances. The sphericity of the matrix assumption for repeated-measures ANOVA was assessed with the Mauchley sphericity test; when the outcome of the test was significant, the $F$ values were corrected using the Greenhouse-Geisser approach (Glantz and Slinker, 2000). A Newman-Keuls post hoc test was used to establish differences in means after the ANOVA. When requirement for parametric statistic were not met, a Kruskal-Wallis test was used to compare between-group differences. Outliers were determined by using the modified Thompson tau test.

\section{Results}

\section{VTA neurons display a mixed population response to intravenous cocaine}

In vivo recordings were obtained from 248 spontaneously active neurons within the VTA. These neurons exhibited a wide range of discharge rates (from 0.02 to $32.75 \mathrm{~Hz}$ ); $82 \%$ changed their discharge rates in response to intravenous administration of cocaine. Neurons were classified as responding to cocaine when their discharge rates increased or decreased by at least $20 \%$ from 
A

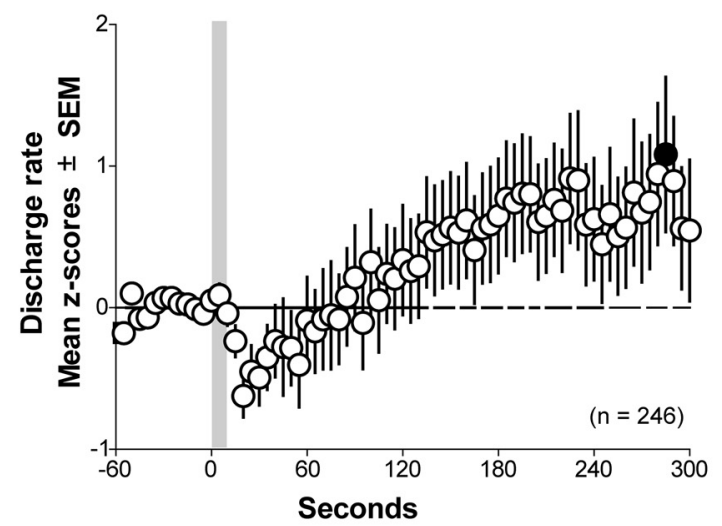

C

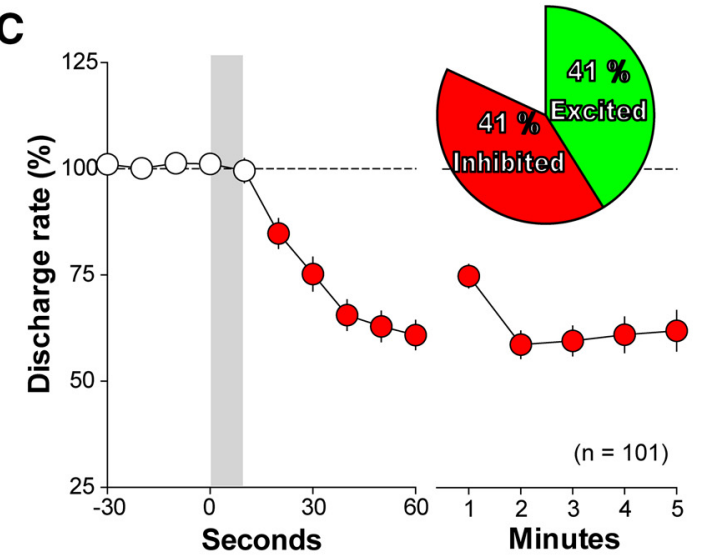

B

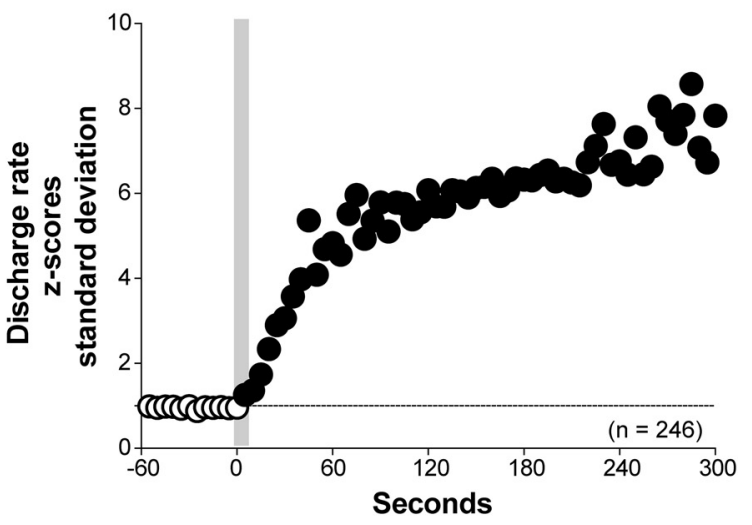

D

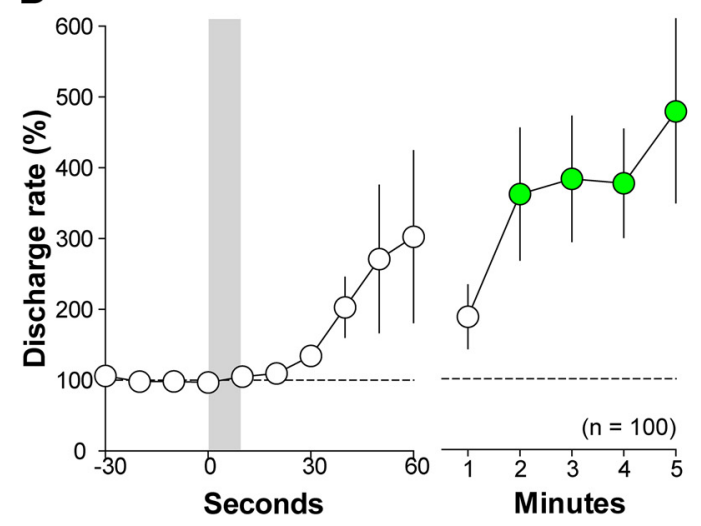

Figure 1. Onset latency and duration of cocaine-evoked response. $A$, Mean population response. There is an increase in firing rate variability as indicated by the increase in amplitude of the SEMs. $B$, Discharge rate SD. Changes in discharge rate emerge immediately after the initiation of cocaine infusion and remain throughout 5 min of cellular recordings. $C$, Neurons inhibited by cocaine. Discharge rates decrease $20 \mathrm{~s}$ after intravenous cocaine. $\boldsymbol{D}$, Neurons excited by cocaine. Discharge rates increase within $2 \mathrm{~min}$ after intravenous cocaine. Filled circles show differences from baseline discharge rates. Errors bar are SEM.

their baseline for a minimum of $30 \mathrm{~s}$. The proportion of VTA neurons inhibited by cocaine $(41 \%, 101$ of 248 cells) was similar to that of the excited neurons ( $41 \%, 102$ of 248 cells; Fig. 1A).

To determine the net VTA neural activity evoked by intravenous cocaine, we pooled the discharge rates from cocaineexcited, cocaine-inhibited, and cocaine-unresponsive neurons. The discharge rates were normalized using $\mathrm{Z}$ scores determined from the discharge rates before intravenous cocaine administration. Two neurons were classified as outliers and were excluded from the population analysis. These outliers were slow discharge rate neurons whose heightened discharge rates, when excited by cocaine, placed them outside the magnitude of changes exhibited by most VTA neurons ( $>50$ SDs). From the pool of analyzed neurons, we observed an initial trend toward inhibition $(\sim 30 \mathrm{~s}$ after cocaine injection), followed by an excitation $150 \mathrm{~s}$ after the injection, which reached significance at $225 \mathrm{~s}$ after the injection. The population mean discharge rate showed a dominant excitation (repeated-measures ANOVA, $F_{(4,916)}=4.57$, GreenhouseGeisser corrected, $p=0.0011$; Fig. $1 A$ ).

To determine the onset and the duration of the population activity, we used the SD of the discharge rate to remove the directional changes of the two opposite responses evoked by cocaine. We observed that the neuronal activity within the VTA changed within the first $5 \mathrm{~s}$ of the $10 \mathrm{~s}$ duration of cocaine administration. This change was long lasting and was sustained throughout the 5 min of recordings (Fig. 1B). This prolonged response is consistent with previous findings in which responses of individual VTA neurons last for $>5 \mathrm{~min}$ after intravenous cocaine administration (Einhorn et al., 1988; Steffensen et al., 2008).

\section{Some VTA neurons are excited but others are inhibited in response to intravenous cocaine administration}

Most VTA neurons were either excited or inhibited by cocaine. In rare instances, excitation followed inhibition (3 of 248 neurons) or inhibition followed excitation ( 5 of 248 neurons). The onset for inhibition was $20 \mathrm{~s}$ after cocaine injection (repeated-measures ANOVA, $F_{(3,234)}=0.415$, Greenhouse-Geisser corrected, $p<$ 0.001 , Newman-Keuls post hoc test, $p<0.05$ ). Although excitation did not reach significance within the first minute after cocaine injection, it was significantly increased by $2 \mathrm{~min}$ (repeated-measures ANOVA, $F_{(2,203)}=6.04$, Greenhouse-Geisser corrected, $p=0.002$, Newman-Keuls post hoc test, $p<0.05$ ). Both inhibition and excitation peaked at $2 \mathrm{~min}$ and remained stable for several minutes (Fig. 1C,D). Cocaine inhibition remained significantly different from the predrug discharge rates throughout the $5 \mathrm{~min}$ postinjection period, whereas cocaine excitation was significantly different from the $2-5 \mathrm{~min}$ postinjection period (repeated-measures ANOVA, $F_{(3,263)}=0.548$, Greenhouse-Geisser corrected, $p<0.0001$ for inhibition; ANOVA, $F_{(2,203)}=6.03$, Greenhouse-Geisser corrected, $p=$ 0.002 for excitation; Newman-Keuls post hoc test, $p<0.05$ ). The mean magnitude of inhibition during its plateau from 2 to $5 \mathrm{~min}$ was $60.3 \pm 0.7 \%$ from the baseline, similar to the magnitude observed previously after 0.5 or $1 \mathrm{mg} / \mathrm{kg}$ intravenous cocaine 
A

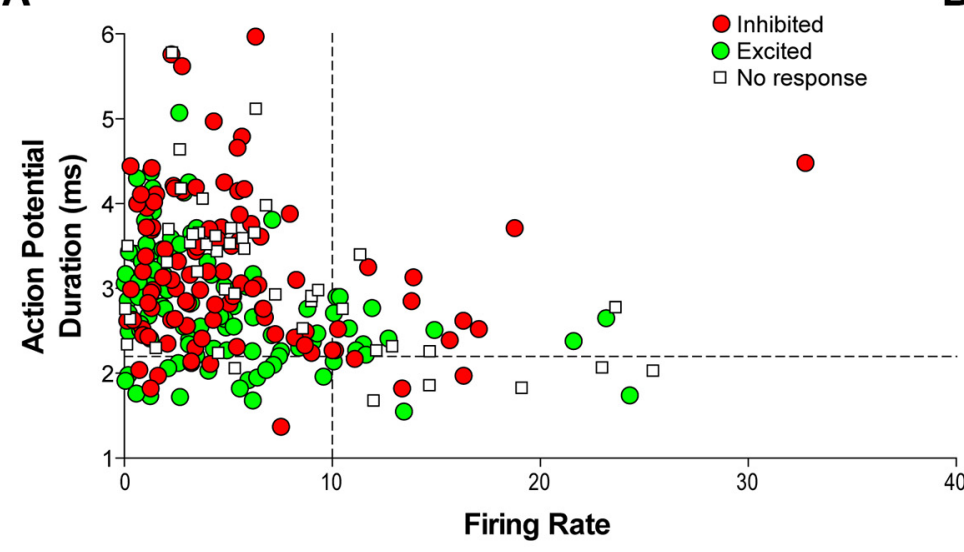

B

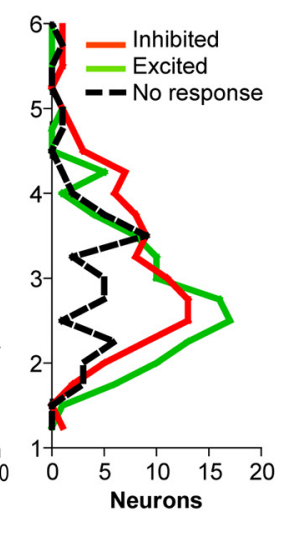

C

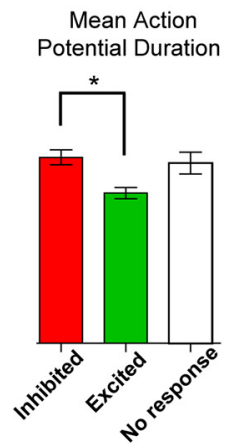

D

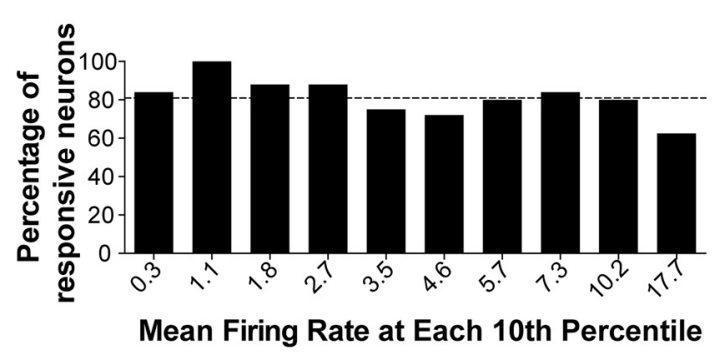

E

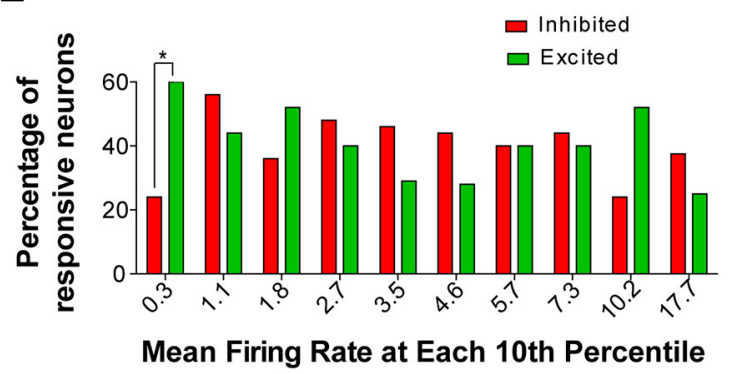

Figure 2. Action potential duration and discharge rate characteristics of cocaine-responsive neurons. $A$, Scatter plot of discharge rate versus action potential duration. Dotted line placed at $10 \mathrm{~Hz}$ on the $x$-axis demarks slow-firing from fast-firing neurons. Dotted line placed at $2.2 \mathrm{~ms}$ on the $y$-axis demarks short-duration from long-duration action potentials. Neither cocaine-excited nor cocaine-inhibited neurons form distinguishable clusters. $B, C$, Frequency distribution and mean action potential duration. Mean action potential duration is shorter in excited neurons than inhibited neurons, but their distributions overlap. D, Proportion of responsive neurons grouped in 10 th percentiles. The dotted line placed at $82 \%$ shows the population percentage of responders. No differences are observed across the percentiles. $E$, Proportions of inhibited and excited neurons grouped in 10 th percentiles. The proportions of responders are similar across different firing rates. Error bars are SEM; ${ }^{*} p<0.05$.

(Einhorn et al., 1988). The mean magnitude of excitation during its plateau from 2 to 5 min was $399.2 \pm 26.3 \%$ from the baseline, onefold higher than the magnitude observed previously in a subgroup of putative VTA GABA neurons after 0.25 and $0.5 \mathrm{mg} / \mathrm{kg}$ intravenous cocaine (Steffensen et al., 2008).

Neurons recorded in vivo have traditionally been assigned neurochemical phenotypes based on their observed electrophysiological properties. In our analysis, neurons that responded to cocaine did not cluster based on their electrophysiological characteristics. No clear population groups were distinguished by plotting discharge rate against action potential duration (Fig. $2 A)$. Cocaine-excited neurons generally displayed shorter action potential durations than cocaine-inhibited neurons (KruskalWallis $K=13.57, p<0.01$, Dunn's multiple comparison test, $p<$ $0.05)$. However, there was considerable overlap in the range of action potential durations between excited neurons and inhibited neurons (Fig. 2B). Initial baseline discharge rate did not correlate with the proportion of neurons that responded to intravenous cocaine (Fig. $2 C$ ) and, except for very slow-firing neurons with mean discharge rates of $0.3 \mathrm{~Hz}$ (Fisher's exact tests, $p<0.001$ ), the number of cocaine-excited neurons was comparable with the number of cocaine-inhibited neurons across a wide range of their spontaneous discharge rates (Fig. 2D). These findings indicate that baseline electrophysiological parameters are not a predictor of how a given VTA neuron would respond to cocaine exposure.

Although the action potential durations of neurons unresponsive to cocaine did not differ from those that were inhibited or excited by cocaine, unresponsive neurons differed from re-
Table 1. Firing regularity of VTA neurons

\begin{tabular}{llll}
\hline & Inhibited & Excited & Unresponsive \\
\hline Rate & $5.20 \pm 0.50$ & $4.94 \pm 0.47$ & $7.18 \pm 0.93^{*}$ \\
CV & $0.81 \pm 0.05$ & $0.92 \pm 0.07$ & $0.69 \pm 0.11^{*}$ \\
CV2 & $0.66 \pm 0.03$ & $0.62 \pm 0.03$ & $0.50 \pm 0.05^{*}$ \\
Fano & $0.74 \pm 0.06$ & $0.85 \pm 0.09$ & $0.52 \pm 0.07^{*}$ \\
\hline
\end{tabular}

*Different from excited and inhibited, $p<0.05$.

sponsive neurons in their discharge rate and firing regularity parameters (Table 1). The mean discharge rate of cocaineunresponsive neurons was higher than those detected in either cocaine-excited or cocaine-inhibited neurons (one-way ANOVA, $F_{(2,247)}=3.43, p<0.05$, Newman-Keuls test, $\left.p<0.05\right)$. In addition, cocaine-unresponsive neurons had smaller CV, CV2, and Fano factor for baseline firing than those observed in cocaine-excited and cocaine-inhibited neurons (CV, Kruskal-Wallis $K=10.98, p<$ 0.01 , Dunn's test $p<0.05$; CV2, one-way ANOVA, $F_{(2,247)}=$ $2.86, p<0.05$; Fano factor, Kruskal-Wallis $K=12.06, p<0.01$, Dunn's test, $p<0.05$ ). These findings indicate that cocaineunresponsive neurons fire faster and exhibit a more regular firing pattern than cocaine-responsive neurons.

\section{Intravenous cocaine administration does not elicit a strong} change in burst firing

Because previous studies have suggested that burst firing of DA neurons might play a role in cocaine sensitization and conditioned place preference (Zweifel et al., 2008, 2009), we determined whether the tonic changes produced by intravenous 
A

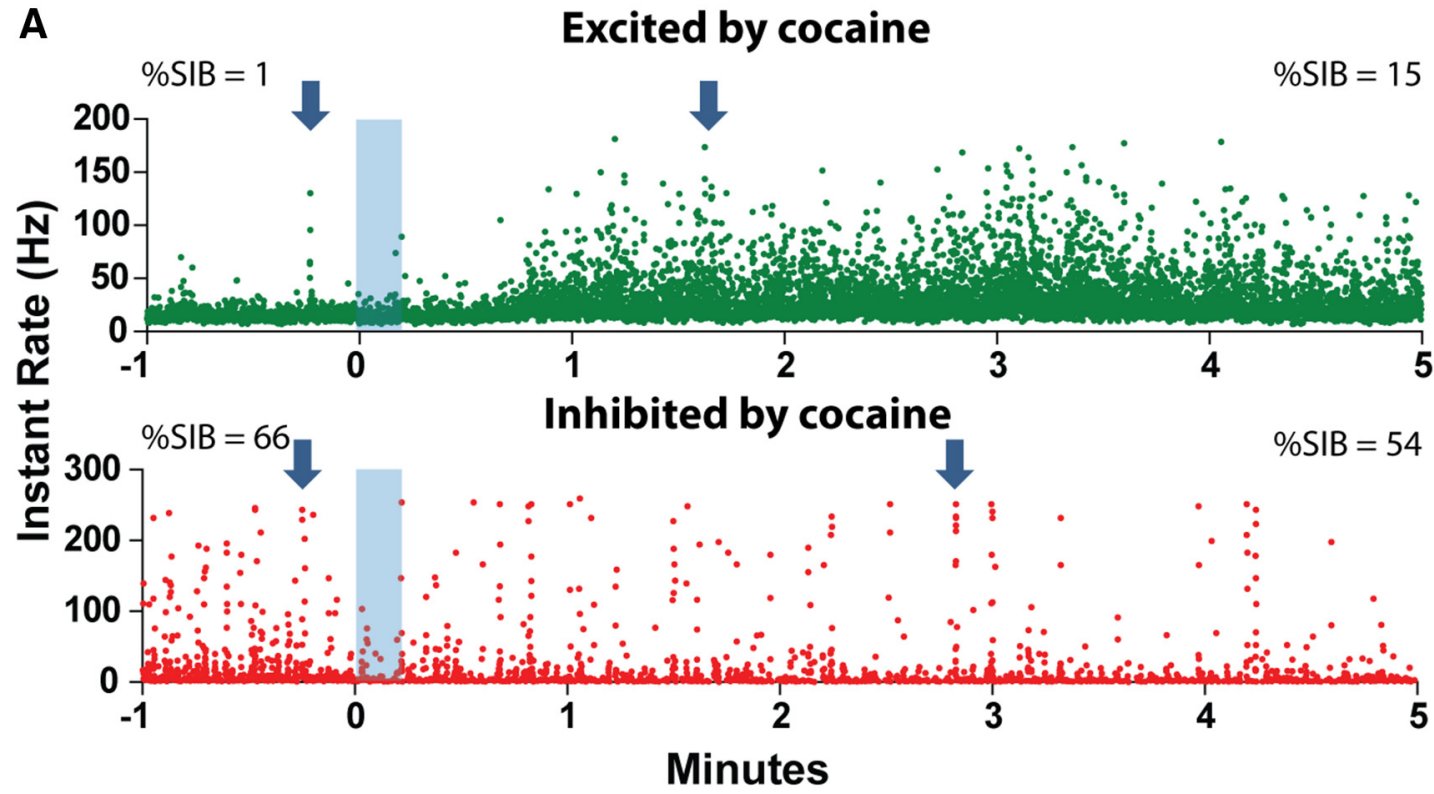

B

Excited by cocaine

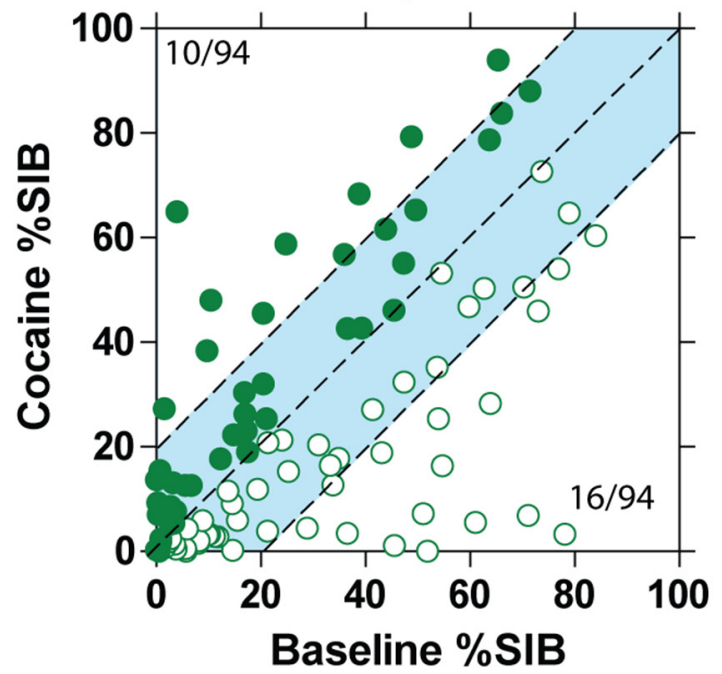

Inhibited by cocaine

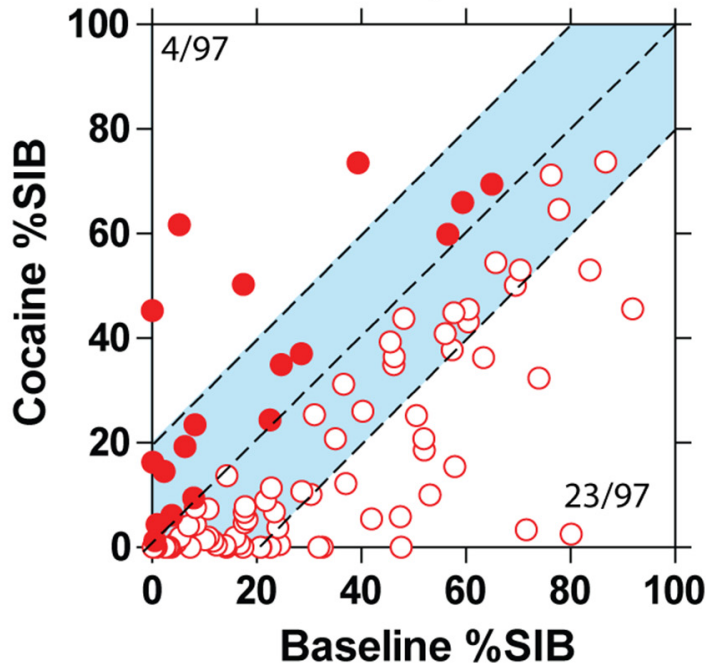

Figure 3. Burst firing in VTA neurons is mostly unperturbed by cocaine. $\boldsymbol{A}$, Two sample traces. The top trace shows a cocaine-excited neuron that increases the percentage of SIB after intravenous cocaine. The bottom trace shows a cocaine-inhibited neuron that decreases the percentage of SIB after intravenous cocaine. Bursts align in columns of spikes with high-frequency rates. Example burst are highlighted by the arrows. $\boldsymbol{B}$, Baseline SIB versus cocaine SIB. The left side shows changes in burst firing in cocaine-excited neurons. The right side shows changes in burst firing in cocaine-inhibited neurons. Notice that most neurons are within $<20 \%$ change in their SIB, highlighted in light blue.

cocaine alter burst firing on VTA neurons. We analyzed the percentage of spikes in burst (SIB) for each neuron before and after cocaine. Of the 203 cocaine-responsive neurons, 12 neurons were excluded from the analysis because no burst activity was observed. Of the 191 neurons analyzed, 94 were cocaine-excited neurons and 97 were cocaine-inhibited neurons. We did not find differences in SIB between the two groups (two-way ANOVA, $F_{(1,189)}=0.077, p=0.78$ ). However, within-group evaluation showed that, in the cocaine-excited neurons, the SIB decreased from $30.8 \pm 2.6$ to $19.9 \pm 2.3 \%$ after cocaine exposure (Newman-Keuls test, $p<0.05$ ). In cocaine-inhibited neurons, the SIB was maintained at similar levels before $(28 \pm 2.5 \%)$ and after $(24.5 \pm 2.5 \%)$ cocaine administration.

To further characterize changes in the SIB after intravenous cocaine, we subdivided the neurons into three groups: (1) neurons that exhibited $>20 \%$ increase in their SIB; (2) neurons with $<20 \%$ changes in their SIB; and (3) neurons that exhibited $>20 \%$ decrease in their SIB. Among cocaine-excited neurons, approximately onequarter displayed SIB changes of $>20 \%$ in magnitude; of these neurons, $11 \%$ (10 of 94) showed an increase and 17\% (16 of 94) showed a decrease in their SIB. However, the majority of cocaine-excited neurons ( 68 of $94,72 \%$ ) showed SIB changes of $<20 \%$ in magnitude (Fig. 3B, blue highlight). Among cocaine-inhibited neurons, approximately one-quarter of them exhibited SIB changes of $>20 \%$ in magnitude; of these neurons, $4 \%$ (4 of 97) showed an increase and $24 \%$ ( 23 of 97 ) showed a decrease in their SIB. In the majority of cocaine-inhibited neurons (70 of $97,72 \%$ ), the SIB changes were $<20 \%$ in magnitude (Fig. 3B, blue highlight).

Cocaine-inhibited neurons are more predominant in the posterior VTA

Our recordings covered medial parts of the VTA, as well as the interfascicular, rostral linear, and caudal linear nuclei of the raphe, all constituents of the DA area collectively called A10 (Dahl- 


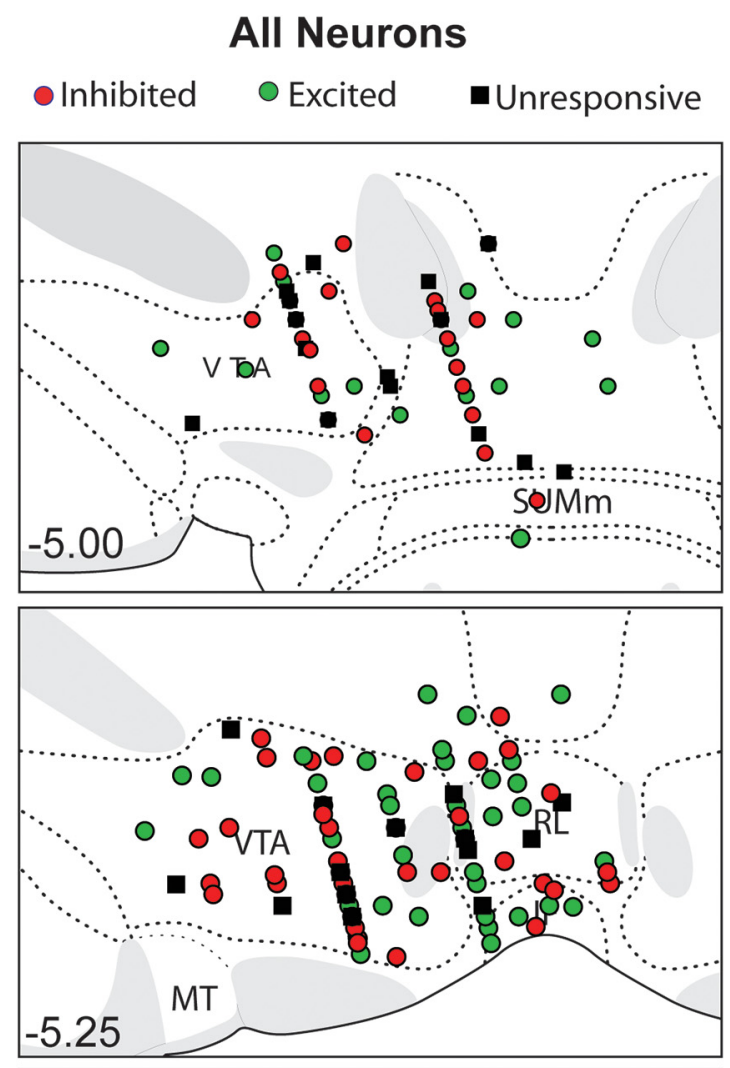

\section{Juxtacellularly Labeled Neurons \\ DA Inhibited O Excited non-DA $\nabla$ Inhibited $\nabla$ Excited *Unresponsive}
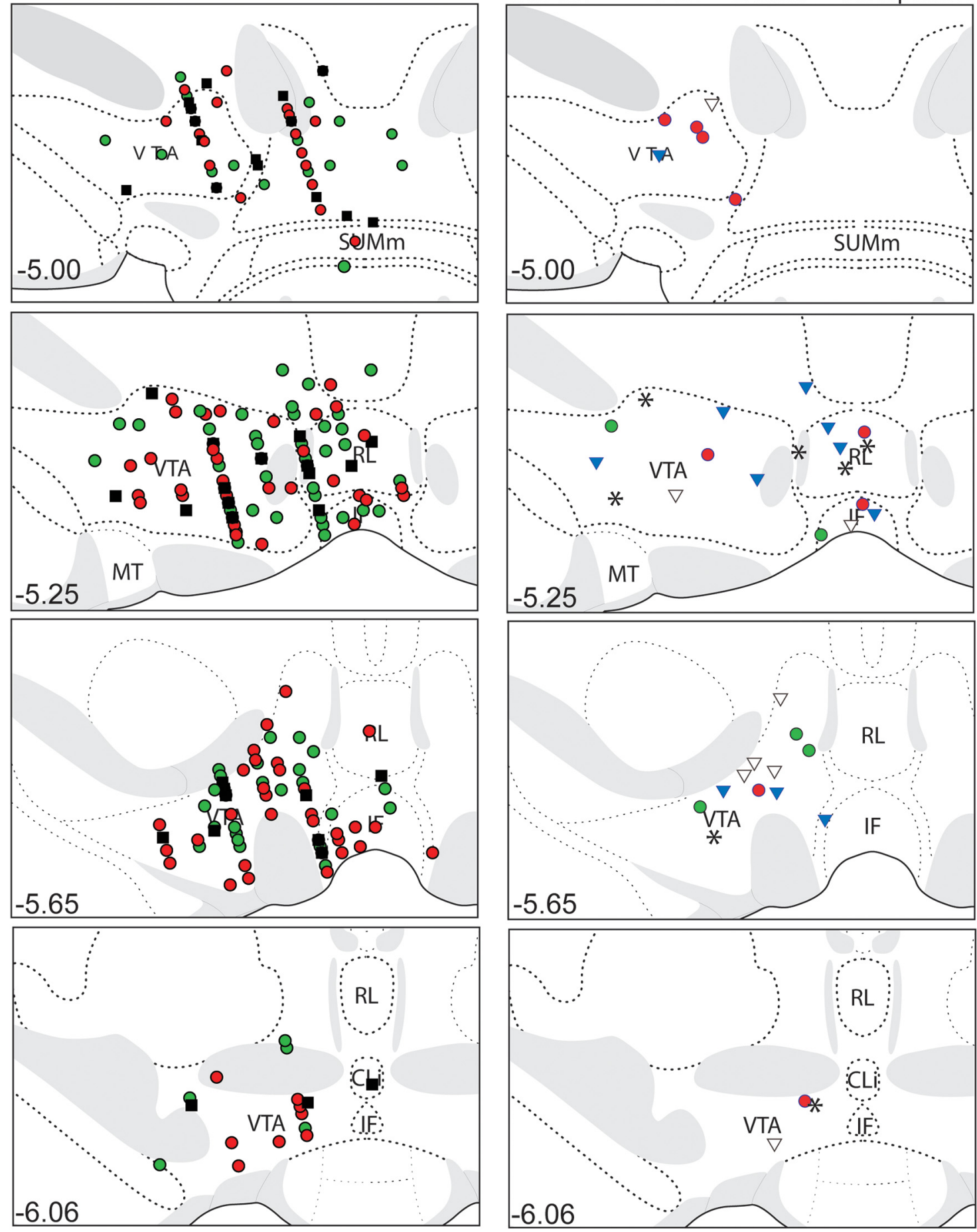

Figure 4. Placements of recorded neurons across the VTA. Anterior VTA recordings at -5.0 and $-5.3 \mathrm{~mm}$ from bregma. Posterior VTA recordings at -5.7 and $-6.0 \mathrm{~mm}$ from bregma. RL, Rostral linear nucleus; IF, interfascicular nucleus; SUMm, medial supramammillary nucleus; CLi, caudal linear nucleus; MT, medial terminal nucleus of the accessory optic tract.

stroem and Fuxe, 1964). Neurons located anterior to or at bregma $-5.3 \mathrm{~mm}$ were considered to reside within the anterior VTA, and those located posterior to bregma $-5.3 \mathrm{~mm}$ were considered to reside within the posterior VTA (Fig. 4). This categorization was selected based on previous reports showing differential actions of drug delivered either in the anterior or posterior aspects of bregma $-5.3 \mathrm{~mm}$ (McBride et al., 1999; Ike- moto and Wise, 2004). We found that the proportion of cocaineinhibited neurons was higher in the posterior VTA (46 of 92) than in the anterior VTA ( 55 of 159; Fisher's exact test, $p<0.05$; Fig. 5). No differences were observed in the proportion of cocaine-excited neurons present in the anterior versus the posterior portions of the VTA. We also analyzed the mediolateral axis using $0.6 \mathrm{~mm}$ mediolateral as the division line, but we did not 


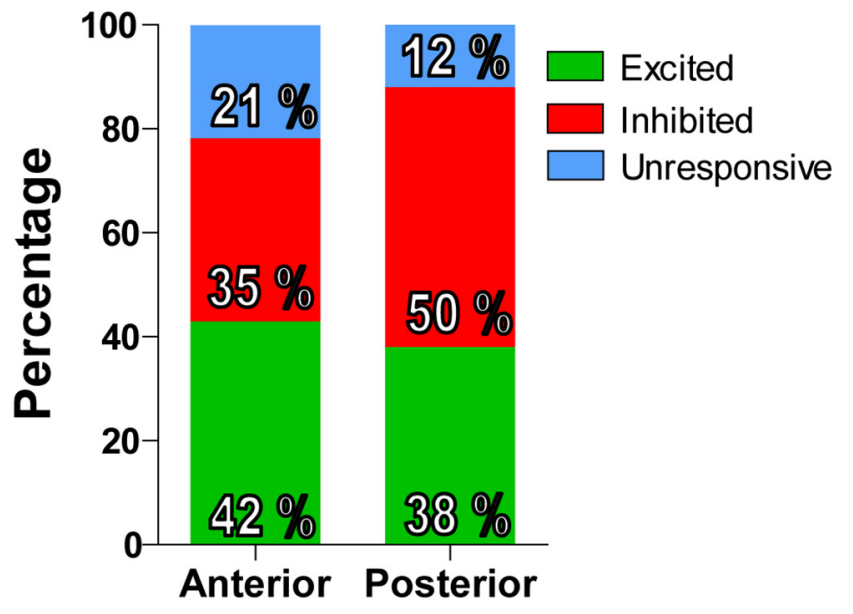

Figure 5. Anatomical differences in the proportion of cocaine-responsive neurons. The proportion of excited neurons is similar in the anterior and posterior VTA. The proportion of cocaineinhibited neurons is higher in the posterior VTA compared with the anterior VTA.

Table 2. Summary of the onset latency and duration of excitatory and inhibitory responses of VTA neurons to footshock

\begin{tabular}{|c|c|c|c|c|}
\hline & \multicolumn{2}{|l|}{ Cocaine-excited } & \multicolumn{2}{|l|}{ Cocaine-inhibited } \\
\hline & $\begin{array}{l}\text { Excited by } \\
\text { footshock }\end{array}$ & $\begin{array}{l}\text { Inhibited by } \\
\text { footshock }\end{array}$ & $\begin{array}{l}\text { Excited by } \\
\text { footshock }\end{array}$ & $\begin{array}{l}\text { Inhibited by } \\
\text { footshock }\end{array}$ \\
\hline $\begin{array}{r}\text { Responsive } \\
\text { neurons }\end{array}$ & 21 of $55(38.2 \%)$ & 7 of $55(12.8 \%)$ & 11 of $53(20.8 \%)$ & 9 of $53(17.0 \%)$ \\
\hline Onset (ms) & $95.5 \pm 28.2$ & $107.1 \pm 31.7$ & $54.2 \pm 16.3$ & $77.8 \pm 18.8$ \\
\hline $\begin{array}{c}\text { Duration } \\
\text { (ms) }\end{array}$ & $454.5 \pm 63.8$ & $407.1 \pm 106.0$ & $395.8 \pm 66.3$ & $238.9 \pm 88.1$ \\
\hline $\begin{array}{r}\text { Magnitude } \\
\text { (spikes) }\end{array}$ & $102.1 \pm 19.8$ & $-197.0 \pm 132.6$ & $122.4 \pm 42.0$ & $-87.4 \pm 18.9$ \\
\hline
\end{tabular}

detect any relationship between the mediolateral location of the recorded neurons and their response to cocaine.

\section{Neurons excited by cocaine are more likely to be excited than to be inhibited by footpad stimulation}

VTA neurons have been categorized previously with respect to their responses to noxious stimuli, such as tail pinch and footpad stimulation (Ungless et al., 2004; Luo et al., 2008). We determined whether VTA neural responses to high-intensity $(10 \mathrm{~mA}$, $0.5 \mathrm{~ms}$ ) footpad stimulation correlated with any VTA neural response to cocaine. We found that, in response to footpad stimulation, 32 of 112 tested neurons were excited and 18 were inhibited (Table 2). Within the population of cocaine-excited neurons, the prevalence of neurons excited by footpad stimulation was higher than the prevalence of neurons inhibited by footpad stimulation (21 excited vs 7 inhibited, Fisher's exact test, $p=$ 0.0039; Fig. 6). Within the population of cocaine-inhibited neurons, the proportion of footpad-excited neurons was similar to that of the neurons inhibited by footpad stimulation.

Cocaine responses do not correlate with the synchrony between the activity in the VTA and PFC

Previous studies have shown an interrelation between the activity of VTA and PFC neurons. Many VTA neurons fire coherently with PFC activity. Some of these neurons exhibit a slow oscillation that is dependent on PFC inputs (Gao et al., 2007). We investigated whether VTA neurons that synchronize PFC EEG are affected by intravenous cocaine. Within the cocaine-excited neurons, most of them $(84.7 \%, 83$ of 98$)$ showed coherence with
PFC EEG within the range of 0.3-2 Hz. Similarly, coherence with PFC was found in cocaine-inhibited neurons (90.6\%, 87 of 96). However, no differences were observed in the distribution of frequencies in which coherence was observed or in the phase relation between PFC and cocaine-excited or cocaine-inhibited neurons (Fig. 7E).

\section{TH-positive and TH-negative neurons are excited by} intravenous cocaine

Thirty-nine neurons were juxtacellularly labeled after characterizing their responses to intravenous cocaine. Fourteen of these were immunopositive for $\mathrm{TH}$ ( $\mathrm{TH}$-positive), whereas the other 25 were immunonegative (TH-negative). All TH-positive neurons responded to intravenous cocaine; 9 were inhibited and 5 were excited (Fig. 8A). Of the $25 \mathrm{TH}$-negative neurons, $64 \%$ responded to intravenous cocaine; 7 were inhibited and 11 were excited (Fig. 8B). Similar proportions of TH-positive and THnegative neurons were excited by cocaine (5 of $14 \mathrm{TH}$-positive neurons, 36\%; and 11 of 25 TH-negative neurons, 44\%; Fisher's exact test, $p=0.74)$. However, the likelihood of TH-positive neurons to be inhibited by cocaine was higher than that of THnegative neurons ( 9 of $14 \mathrm{TH}$-positive neurons, $64 \%$ vs 7 of 25 TH-negative neurons, 28\%; Fisher's exact test, $p<0.05$ ).

Both $\mathrm{TH}$-positive and $\mathrm{TH}$-negative neurons displayed similar electrophysiological characteristics. Most of the recorded neurons $(31$ of $39,79 \%)$ exhibited slow discharge rates $(<10 \mathrm{~Hz})$ and long-duration action potentials $(>2.2 \mathrm{~ms}$; Fig. $9 A)$. None of the $\mathrm{TH}$-positive neurons fired at a rate exceeding $10 \mathrm{~Hz}$. Firing regularity was similar across both groups. Some TH-negative neurons fired very regularly, as shown in the analysis of CV2 and Fano parameters (Fig. 9C), a characteristic that was not observed among many TH-positive neurons. Analysis of the SIB showed that most $\mathrm{TH}$-positive and $\mathrm{TH}$-negative neurons did not exhibit great changes in SIB [11 of 14 (79\%) and 13 of $17(76 \%)$, respectively], and SIB changed $<20 \%$ in magnitude (Fig. 9D, blue highlight).

All neurochemically characterized neurons were within the A10 region: 27 within the VTA, five within the interfascicular nucleus, and six within in the rostral linear nucleus of the raphe (Fig. 4).

Five neurons excited by footpad stimulation were juxtacellularly labeled. Three of these were DA neurons excited by cocaine, one was a non-DA neuron excited by cocaine, and one was non-DA neuron inhibited by cocaine. Two neurons inhibited by footpad stimulation were juxtacellularly labeled, both non-DA: one was excited by cocaine, and the other was inhibited by cocaine. Seven neurons unresponsive to footpad stimulation were also labeled: two were DA and five were non-DA.

\section{Discussion}

In the present study, we provide in vivo electrophysiological and neurochemical evidence indicating that systemic administration of cocaine either excites or inhibits neurochemically identified VTA DA neurons. Previous in vivo electrophysiological studies have shown that putative VTA DA neurons are inhibited by systemic cocaine administration (Einhorn et al., 1988; Hinerth et al., 2000; Zhou et al., 2006). However, other studies have shown that some putative DA neurons are excited by cocaine (Brown and Kiyatkin, 2008; Koulchitsky et al., 2012; Mejías-Aponte and Kiyatkin, 2012). The importance of neurochemical identification of VTA recorded neurons is becoming apparent, because accumulating evidence indicates similar electrophysiological characteristics between VTA subpopulations of non-DA neurons and DA 
A

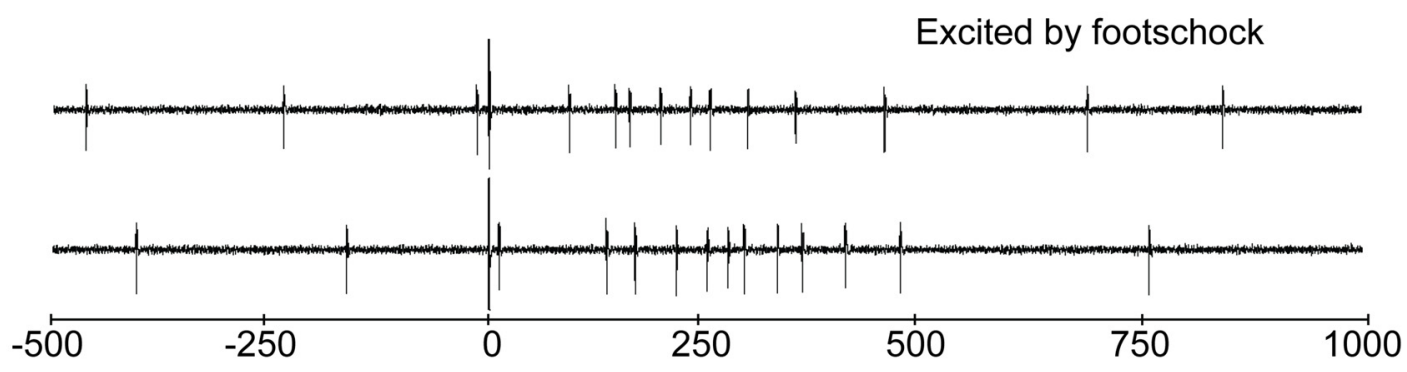

B
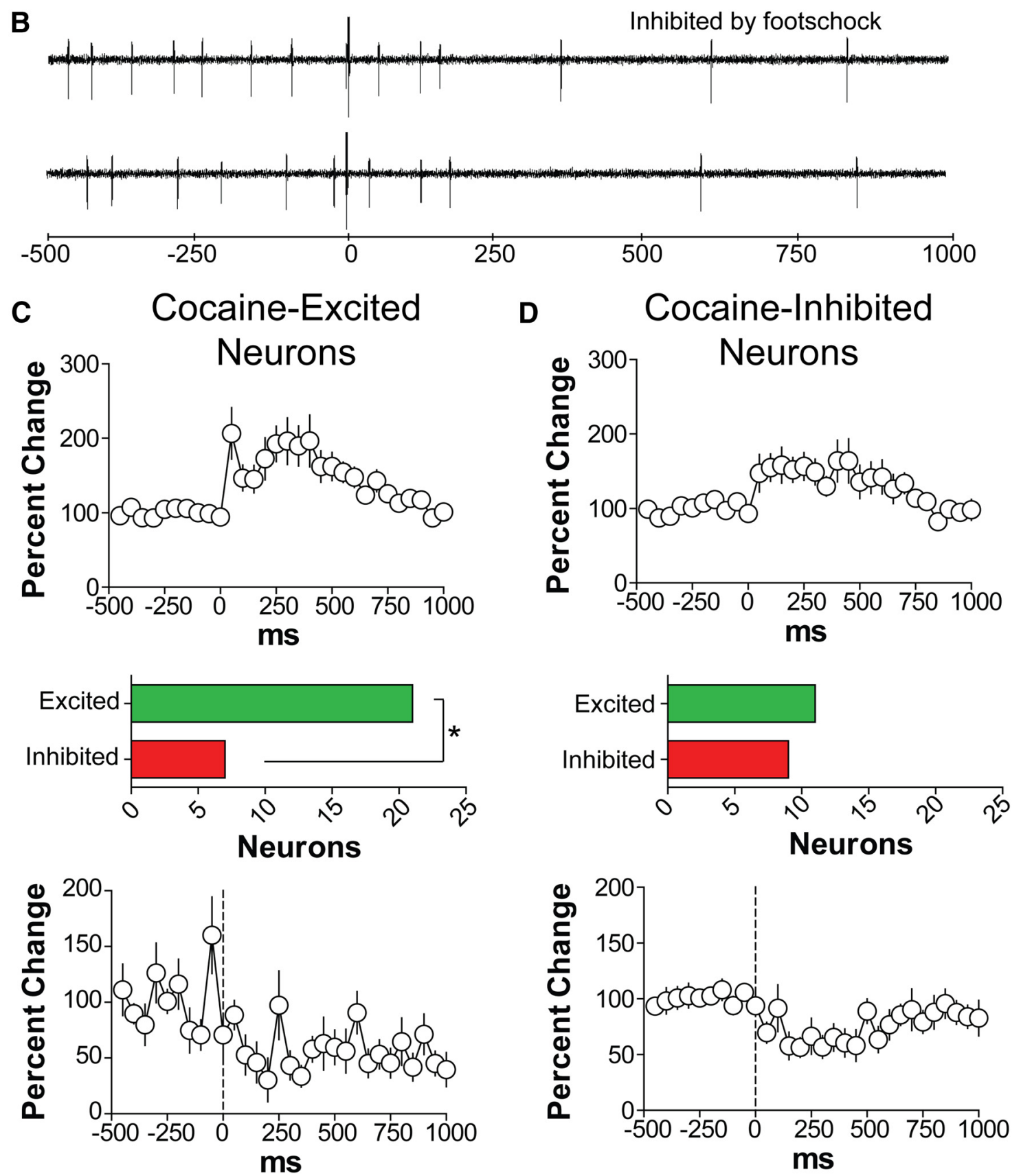

Figure 6. VTA neurons are either excited or inhibited by footpad stimulation ( $10 \mathrm{~mA}, 0.5 \mu \mathrm{s}$ at $2 \mathrm{~Hz}) . A, B$, Examples of footpad-responsive neurons, one excited and the other inhibited. C, Population response of cocaine-excited neurons to footpad stimulation. Notice that the proportion of excited neurons was higher than the proportion of inhibited neurons by footpad stimulation (Fisher's exact test, $p<0.01$ ). D, Population response of cocaine-excited neurons to footpad stimulation. Similar proportions of neurons were excited and inhibited by footpad stimulation. Error bars are SEM. 


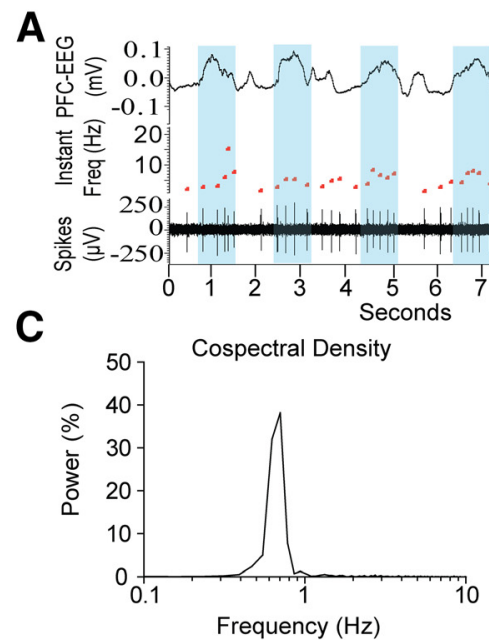

D Frequency of Peak Coherence - Cocaine-excited - Cocaine-inhibited

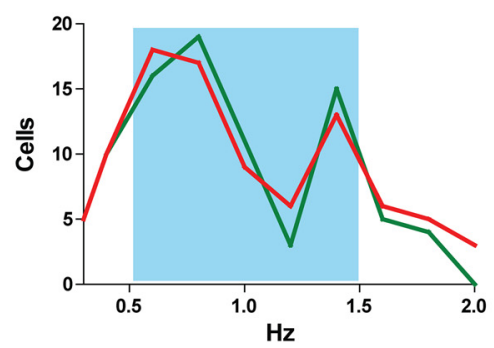

B
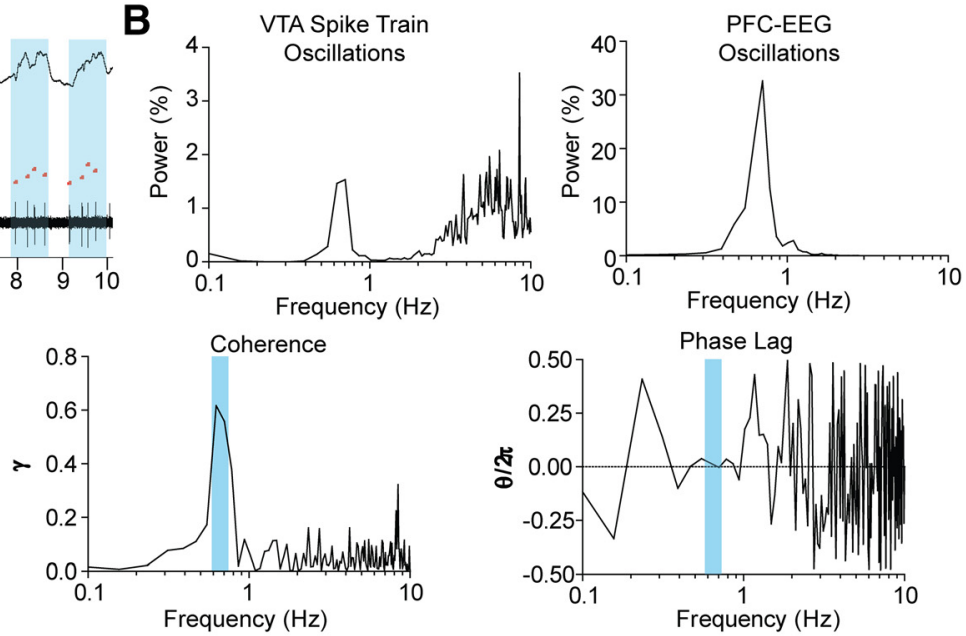

E

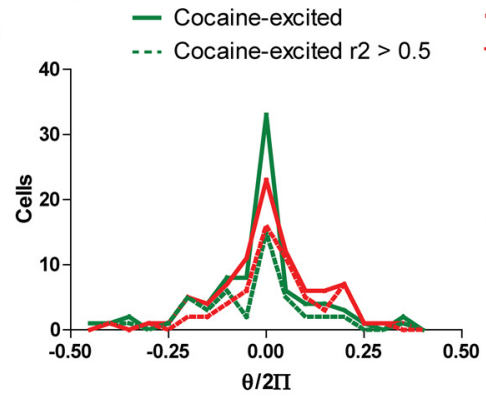

Phase Lag

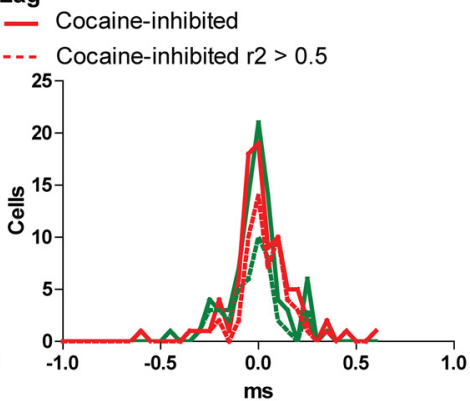

Figure 7. Synchrony between VTA cocaine-responsive neurons and PFCEEG. $\boldsymbol{A}$, A VTA neuron increasing its firing during the up state of PFCEEG. Up EEG periods are highlighted in blue. Notice that the time between spikes is shorter during the up periods, exemplified with an increase in the instant rate (red trace of the record) $\boldsymbol{B}$, Both the spike train and PFC EEG exhibit a slow oscillation. $\boldsymbol{C}$, Cospectral density, coherence, and phase lag between VTA spike train and PFCEEG. The blue bar shows the frequency of highest coherence and its phase lag. This neuron shows an in-phase synchrony with PFC EEG. D, Frequency of peak coherence among cocaine-excited and cocaine-inhibited neurons. No differences are observed in their frequency distributions. $\boldsymbol{E}$, Phase lag between VTA spike trains and PFC EEG oscillations. Many VTA neurons fired in-phase with PFC. No differences are observed in the distributions of cocaine-excited and cocaine-inhibited neurons.

neurons (Ungless et al., 2004; Margolis et al., 2006; Luo et al., 2008; Cohen et al., 2012). Here, we combined in vivo juxtacellular labeling of recorded neurons with post hoc neurochemical identification of TH, a marker for DA neurons, and determined that both cocaine-inhibited and cocaine-excited neurons are present among TH-positive and TH-negative neurons. Our findings indicate that DA neurons are heterogeneous in their response to cocaine and that VTA non-DA neurons exhibit responses to systemic cocaine similar to those observed among DA neurons.

\section{Cocaine induces strong excitation in a subset of VTA neurons} Although previous in vivo studies had determined the effects of intravenous cocaine on preselected populations of neurons based on electrophysiological criteria (Einhorn et al., 1988; Marinelli et al., 2003; Steffensen et al., 2008), we analyzed cocaine effects on VTA neurons regardless of their basic electrophysiological properties. In addition, we determined the effects of cocaine on neurons within different subdivisions of the dopaminergic area A10, because subdivisions of this area have different cellular composition and connectivity (Dahlstroem and Fuxe, 1964; Swanson, 1982; Deutch et al., 1991; Yamaguchi et al., 2011). By recording without preselection (based on electrophysiological cellular properties), we found a similar prevalence of neurons that are excited $(41 \%)$ or inhibited $(41 \%)$ by cocaine. The magnitude of the inhibition is favored within the first minute after the injection, but excitation becomes a stronger component after 2 min.
These findings indicate that systemic cocaine evokes a prolonged cellular excitation within the VTA.

\section{Both DA and non-DA neurons change their discharge rates in} response to systemic cocaine

A major finding of this study is that both DA and non-DA neurons have similar responses to systemic cocaine. However, the proportions of responders in relation to cell type were different between DA and non-DA neurons. We found that, although the prevalence of TH-positive and TH-negative neurons excited by cocaine is similar, TH-positive neurons are twice as often more likely to be inhibited by cocaine than TH-negative neurons.

We found that the electrophysiological characteristics of VTA neurons are poor predictors of how these neurons may respond to cocaine or what their neurochemical phenotype may be. Cocaine-excited and cocaine-inhibited neurons have similar discharge rates and firing regularities. Cocaine-excited neurons have significantly shorter action potential durations than those of cocaine-inhibited neurons. Nevertheless, there is considerable overlap between their distributions. Similarly, within the group of juxtacellularly labeled neurons, the categories of cocaineexcited and cocaine-inhibited neurons are found within the subpopulations of $\mathrm{TH}$-positive and $\mathrm{TH}$-negative neurons. These four subclasses of neurons share many common electrophysiological characteristics. The only notable difference among them is in their discharge rate; some TH-negative neurons, but none of 
A
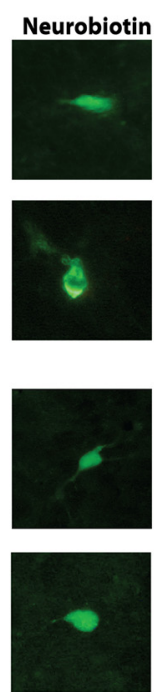

B
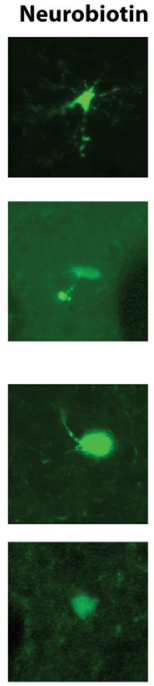
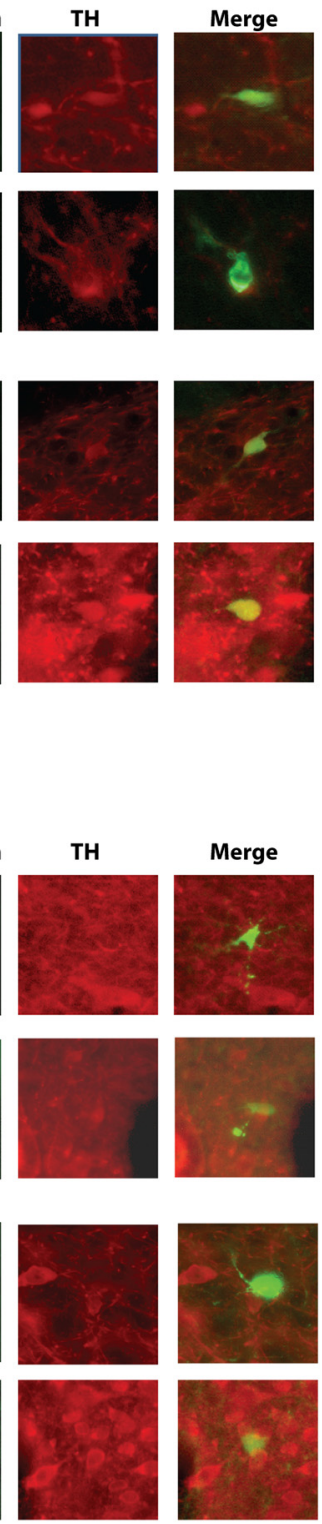

TH+

\section{Excited Neurons}
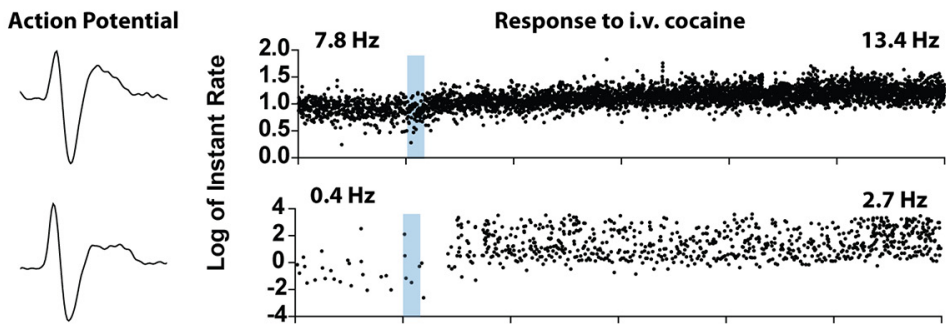

Inhibited Neurons
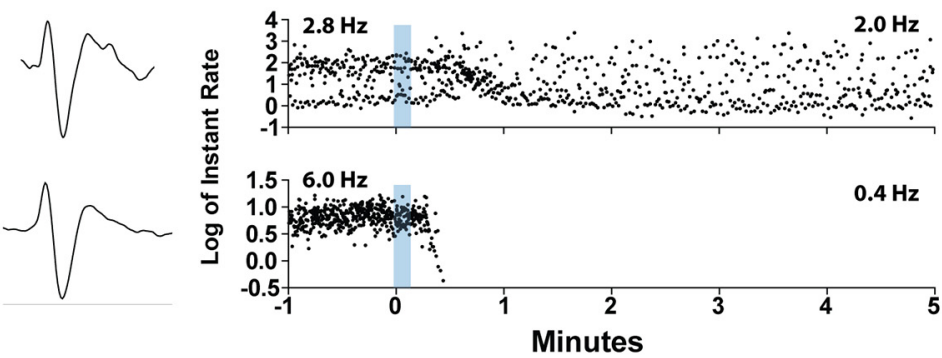

TH-

Excited Neurons

Action Potential<smiles>CCCCCC</smiles>
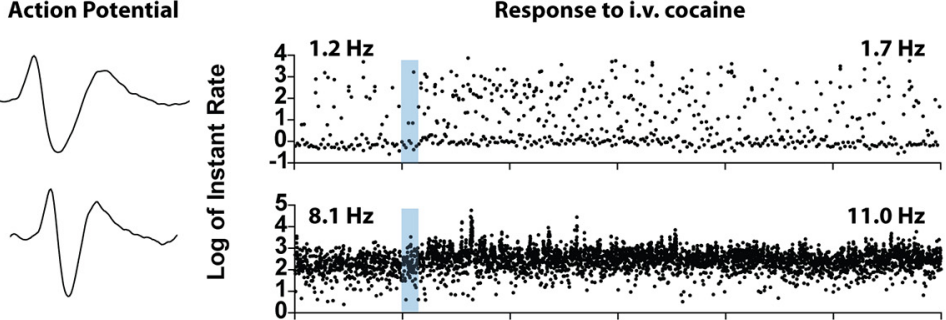

Inhibited Neurons

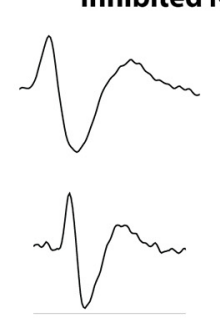

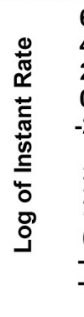

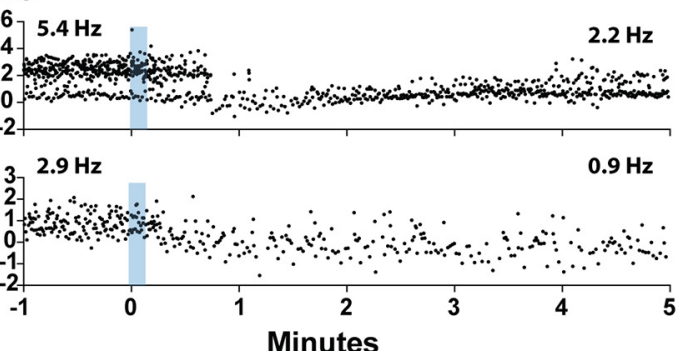

Figure 8. Examples of TH-positive and TH-negative neurons labeled after recording their responses to intravenous cocaine. $A$, TH-positive neurons. The top rows show two cocaine-excited DA neurons. The bottom rows show two cocaine-inhibited DA neurons. $\boldsymbol{B}$, TH-negative neurons. The top rows show two cocaine-excited non-DA neurons. The bottom rows show two cocaine-inhibited non-DA neurons. Recording traces are shown in instant rate, the time difference between subsequent action potentials.

the TH-positive neurons, fired above $10 \mathrm{~Hz}$, indicating that VTA fast-firing cocaine-responsive neurons may be GABA or glutamate neurons. The lack of distinguishable electrophysiological characteristics and neurochemical type among cocaine-responsive neurons indicate that they cannot be identified based solely on their electrophysiological properties.

Contrary to cocaine-responsive neurons, cocaine-unresponsive neurons have more defined electrophysiological characteristics. These neurons have a faster and more regular firing than cocaineexcited or cocaine-inhibited neurons. Within the group of juxtacellularly labeled neurons, all cocaine-unresponsive neurons were TH negative, indicating that these neurons belong to either VTA GABA or glutamate neurons. Although a fast and regular firing is often attributed to putative GABA neurons (Steffensen et al., 1998; Li et al., 2012), slow-firing GABA neurons have been found in the VTA (Tan et al., 2012). Moreover, the in vivo electrophysiological features of VTA glutamate neurons in vivo are unknown. Thus, the accurate determination of the phenotype of TH-negative cocaine-unresponsive neurons cannot be based currently on their cellular electrophysiological properties.

\section{Many DA neurons are excited by systemic cocaine}

We found a subset of TH-positive neurons excited by cocaine that comprises approximately one-third of the neurochemically identified DA neurons, indicating that excitation of DA neurons by intravenous cocaine is not a rare event. The excitation of DA neurons by cocaine has been suggested previously by electrochemical studies. A recent study has shown that, in the nucleus 


\section{Action potential Duration and Discharge Rate}

A

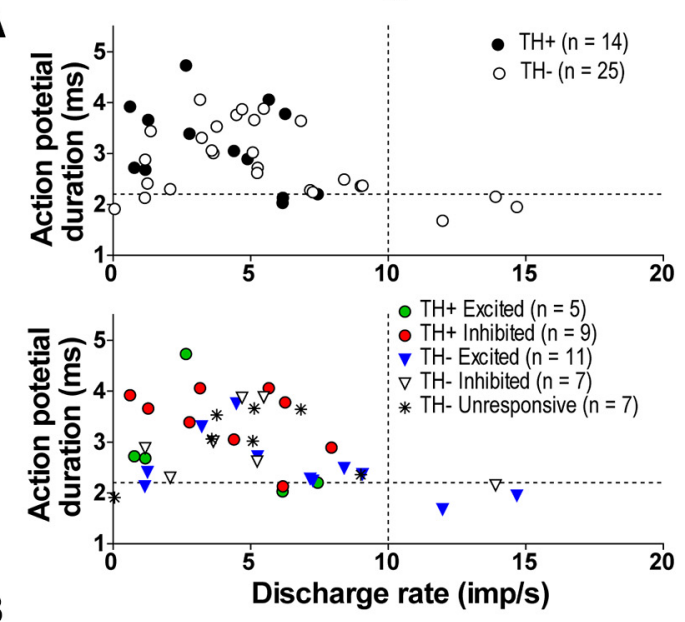

B

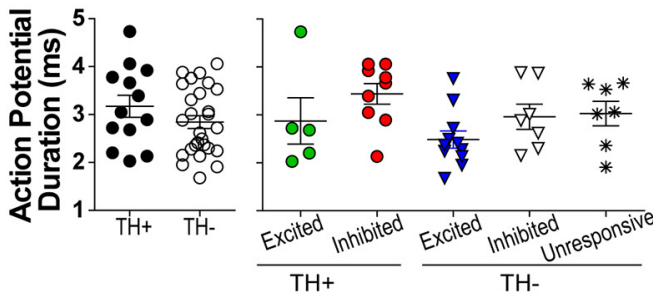

C
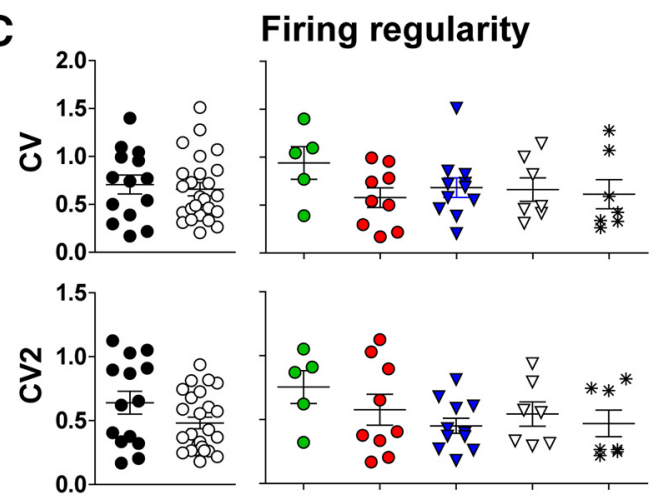
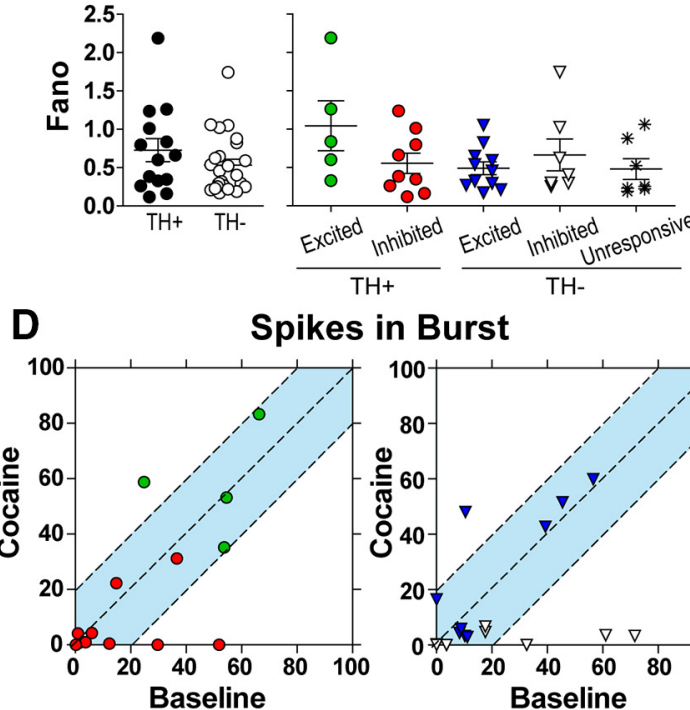

Spikes in Burst

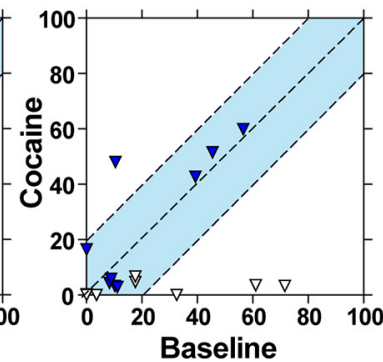

Figure 9. TH-positive and TH-negative neurons share similar electrophysiological characteristics. $A, S$ catter plot of discharge rate versus action potential duration. The dotted line placed at $10 \mathrm{~Hz}$ on the $x$-axis demarks the slow-firing from the fast-firing neurons. The dotted line placed at $2.2 \mathrm{~ms}$ on the $y$-axis demarks neurons with short-duration action potential from those with long-duration action potential. No clear clustering of neurons is observed regardless of whether the neurons are inhibited or excited by intravenous cocaine. TH-positive neurons have short- or long-duration action potentials, but none exhibits discharge rate above $10 \mathrm{~Hz}$. B, Action potential durations. TH-positive and TH-negative neurons do not differ in their action potential durations. $\mathbf{C}$, Firing regularity. TH-positive and TH-negative neurons do not differ in their firing regularity as determined by CV, CV2, and Fano factor. D, Baseline SIB versus cocaine SIB. The left side shows changes in burst firing in TH-positive neurons. The right side shows changes in burst firing in TH-negative neurons. Notice that most neurons are within the changes of $<20 \%$ in their SIB, highlighted in light blue.

accumbens, there is an increase in phasic DA release after intravenous cocaine (Aragona et al., 2008). This phasic increase is sensitive to inactivation of VTA neurons (Sombers et al., 2009), indicating that DA cell activity is necessary for this effect. These electrochemical studies also predicted an increase in burst activity phasic DA release. Consistent with this view, our findings indicate that the burst firing of VTA neurons is relatively unperturbed by cocaine, with changes in VTA burst activity rarely exceeding 20\% above the baseline. In this scenario, the combined postsynaptic blockade of the DA transporter at terminals plus bursting activity in DA neurons can produce the increased number of phasic events in the nucleus accumbens observed with fast cyclic voltammetry.

\section{Role of inputs to VTA in mediating cocaine-induced VTA neural changes}

The lack of a distinctive phenotype among cocaine-responsive neurons in the VTA indicates that other factors, besides intrinsic cellular properties, are influential in determining how a given cell will respond to intravenous cocaine. Distinct inputs to specific populations of VTA neurons may drive divergent cellular responses to cocaine. Evidence in favor of the importance of inputs to the VTA in driving cellular responses to cocaine is provided by studies showing that cocaine methiodide, a cocaine formulation unable to cross the blood-brain barrier and acting only in the periphery, evokes discharge rate increases or decreases in VTA neurons (Mejías-Aponte and Kiyatkin, 2012). The importance of inputs to the VTA in mediating the rate-changing effects of cocaine is also suggested by results showing that hemisection of the forebrain decreases the magnitude of partial inhibition evident in VTA neurons after intravenous cocaine (Einhorn et al., 1988). From these findings, we hypothesize that inputs to VTA neurons play an important role in mediating cocaine responses. To begin addressing this hypothesis, we determined whether inputs to the VTA involved in synchrony with PFC activity or those involved in responses to footpad stimulation predicted VTA responses to cocaine. Although we did not find a correlation between cocaine responses of VTA neurons and PFC activity, we found that a subpopulation of VTA neurons excited by cocaine is more likely to be excited by footpad stimulation. We suggest that some of the VTA neurons excited by cocaine and footpad stimulation receive inputs from brain structures involved in nociception, such as the parabrachial nucleus (Coizet et al., 2010). Because in addition to being rewarding cocaine has aversive properties (Resnick et al., 1977; Blanchard et al., 1999; Ettenberg, 2004), we suggest that VTA cocaine-induced excitation is likely to be related to the aver- 
sive properties of cocaine. Of the neurons excited by footpad stimulation, three were confirmed DA neurons that were also excited by cocaine, thus indicating that cocaine-excited DA neurons are also sensitive to noxious stimulus.

Systemic cocaine increases phasic DA release in the nucleus accumbens (Aragona et al., 2008; Sombers et al., 2009). This cocaine-induced phasic release of DA appears to be mediated, in part, by NMDA-dependent burst firing of DA neurons, because pharmacological inactivation of NMDA glutamate receptors within the VTA decreases phasic DA release induced by cocaine. Here, we found that the busting activity of most of the VTA neurons, including most DA neurons, is not altered after intravenous cocaine administration. These findings suggest that the glutamate inputs driving burst firing in the VTA neurons are not inactivated by systemic cocaine.

In summary, we found that systemic cocaine evokes either excitation or inhibition among VTA neurons. Cocaine induces excitation in both DA and non-DA neurons. Multiple studies indicate that cocaine-induced DA release in the nucleus accumbens is mediated, in part, by interactions between cocaine and the DA transporter. However, the demonstration that a subset of DA neurons is excited by cocaine indicates that cocaine-induced increases of DA release in the nucleus accumbens is produced not only by the effects of cocaine on DA transporters but also by cocaine-induced excitation of VTA DA neurons.

\section{References}

Aragona BJ, Cleaveland NA, Stuber GD, Day JJ, Carelli RM, Wightman RM (2008) Preferential enhancement of dopamine transmission within the nucleus accumbens shell by cocaine is attributable to a direct increase in phasic dopamine release events. J Neurosci 28:8821-8831. CrossRef Medline

Blanchard RJ, Kaawaloa JN, Hebert MA, Blanchard DC (1999) Cocaine produces panic-like flight responses in mice in the mouse defense test battery. Pharmacol Biochem Behav 64:523-528. CrossRef Medline

Booze RM, Lehner AF, Wallace DR, Welch MA, Mactutus CF (1997) Doseresponse cocaine pharmacokinetics and metabolite profile following intravenous administration and arterial sampling in unanesthetized, freely moving male rats. Neurotoxicol Teratol 19:7-15. CrossRef Medline

Brown PL, Kiyatkin EA (2008) Sensory effects of intravenous cocaine on dopamine and non-dopamine ventral tegmental area neurons. Brain Res 1218:230-249. CrossRef Medline

Carr DB, Sesack SR (2000) GABA-containing neurons in the rat ventral tegmental area project to the prefrontal cortex. Synapse 38:114-123. CrossRef Medline

Carroll ME, Lac ST (1997) Acquisition of i.v. amphetamine and cocaine self-administration in rats as a function of dose. Psychopharmacology (Berl) 129:206-214. CrossRef Medline

Cohen JY, Haesler S, Vong L, Lowell BB, Uchida N (2012) Neuron-typespecific signals for reward and punishment in the ventral tegmental area. Nature 482:85-88. CrossRef Medline

Coizet V, Dommett EJ, Klop EM, Redgrave P, Overton PG (2010) The parabrachial nucleus is a critical link in the transmission of short latency nociceptive information to midbrain dopaminergic neurons. Neuroscience 168:263-272. CrossRef Medline

Dahlstroem A, Fuxe K (1964) Evidence for the existence of monoaminecontaining neurons in the central nervous system. I. Demonstration of monoamines in the cell bodies of brain stem neurons. Acta Physiol Scand Suppl SUPPL 232:231-255. Medline

Deutch AY, Lee MC, Gillham MH, Cameron DA, Goldstein M, Iadarola MJ (1991) Stress selectively increases fos protein in dopamine neurons innervating the prefrontal cortex. Cereb Cortex 1:273-292. CrossRef Medline

Dobi A, Margolis EB, Wang HL, Harvey BK, Morales M (2010) Glutamatergic and nonglutamatergic neurons of the ventral tegmental area establish local synaptic contacts with dopaminergic and nondopaminergic neurons. J Neurosci 30:218-229. CrossRef Medline

Einhorn LC, Johansen PA, White FJ (1988) Electrophysiological effects of cocaine in the mesoaccumbens dopamine system: studies in the ventral tegmental area. J Neurosci 8:100-112. Medline

Ettenberg A (2004) Opponent process properties of self-administered cocaine. Neurosci Biobehav Rev 27:721-728. CrossRef Medline

Gao M, Liu CL, Yang S, Jin GZ, Bunney BS, Shi WX (2007) Functional coupling between the prefrontal cortex and dopamine neurons in the ventral tegmental area. J Neurosci 27:5414-5421. CrossRef Medline

Glantz S, Slinker B (2000) Primer of applied regression and analysis of variance. New York: McGraw-Hill.

Grace AA, Bunney BS (1984) The control of firing pattern in nigral dopamine neurons: burst firing. J Neurosci 4:2877-2890. Medline

Hinerth MA, Collins HA, Baniecki M, Hanson RN, Waszczak BL (2000) Novel in vivo electrophysiological assay for the effects of cocaine and putative "cocaine antagonists" on dopamine transporter activity of substantia nigra and ventral tegmental area dopamine neurons. Synapse 38: 305-312. CrossRef Medline

Holt GR, Softky WR, Koch C, Douglas RJ (1996) Comparison of discharge variability in vitro and in vivo in cat visual cortex neurons. J Neurophysiol 75:1806-1814. Medline

Ikemoto S, Wise RA (2004) Mapping of chemical trigger zones for reward. Neuropharmacology 47 [Suppl 1]:190-201.

Kaneoke Y, Vitek JL (1996) Burst and oscillation as disparate neuronal properties. J Neurosci Methods 68:211-223. CrossRef Medline

Kiyatkin EA, Rebec GV (1998) Heterogeneity of ventral tegmental area neurons: single-unit recording and iontophoresis in awake, unrestrained rats. Neuroscience 85:1285-1309. CrossRef Medline

Kiyatkin EA, Smirnov MS (2010) Rapid EEG desynchronization and EMG activation induced by intravenous cocaine in freely moving rats: a peripheral, nondopamine neural triggering. Am J Physiol Regul Integr Comp Physiol 298:R285-R300. CrossRef Medline

Koulchitsky S, De Backer B, Quertemont E, Charlier C, Seutin V (2012) Differential effects of cocaine on dopamine neuron firing in awake and anesthetized rats. Neuropsychopharmacology 37:1559-1571. CrossRef Medline

Li W, Doyon WM, Dani JA (2012) Quantitative unit classification of ventral tegmental area neurons in vivo. J Neurophysiol 107:2808-2820. CrossRef Medline

Luo AH, Georges FE, Aston-Jones GS (2008) Novel neurons in ventral tegmental area fire selectively during the active phase of the diurnal cycle. Eur J Neurosci 27:408-422. CrossRef Medline

Maeda H, Mogenson GJ (1980) An electrophysiological study of inputs to neurons of the ventral tegmental area from the nucleus accumbens and medial preoptic-anterior hypothalamic areas. Brain Res 197:365-377. CrossRef Medline

Margolis EB, Lock H, Hjelmstad GO, Fields HL (2006) The ventral tegmental area revisited: is there an electrophysiological marker for dopaminergic neurons? J Physiol 577:907-924. CrossRef Medline

Margolis EB, Toy B, Himmels P, Morales M, Fields HL (2012) Identification of rat ventral tegmental area GABAergic neurons. PLoS One 7:e42365. CrossRef Medline

Marinelli M, Cooper DC, Baker LK, White FJ (2003) Impulse activity of midbrain dopamine neurons modulates drug-seeking behavior. Psychopharmacology (Berl) 168:84-98. CrossRef Medline

McBride WJ, Murphy JM, Ikemoto S (1999) Localization of brain reinforcement mechanisms: intracranial self-administration and intracranial placeconditioning studies. Behav Brain Res 101:129-152. CrossRef Medline

Mejías-Aponte CA, Kiyatkin EA (2012) Ventral tegmental area neurons are either excited or inhibited by cocaine's actions in the peripheral nervous system. Neuroscience 207:182-197. CrossRef Medline

Morales M, Root DH (2014) Glutamate neurons within the midbrain dopamine regions. Neuroscience 282C:60-68. CrossRef Medline

Omelchenko N, Sesack SR (2009) Ultrastructural analysis of local collaterals of rat ventral tegmental area neurons: GABA phenotype and synapses onto dopamine and GABA cells. Synapse 63:895-906. CrossRef Medline

Resnick RB, Kestenbaum RS, Schwartz LK (1977) Acute systemic effects of cocaine in man: a controlled study by intranasal and intravenous routes. Science 195:696-698. CrossRef Medline

Rosenberg JR, Amjad AM, Breeze P, Brillinger DR, Halliday DM (1989) The Fourier approach to the identification of functional coupling between neuronal spike trains. Prog Biophys Mol Biol 53:1-31. CrossRef Medline

Sombers LA, Beyene M, Carelli RM, Wightman RM (2009) Synaptic overflow of dopamine in the nucleus accumbens arises from neuronal activity in the ventral tegmental area. J Neurosci 29:1735-1742. CrossRef Medline Steffensen SC, Svingos AL, Pickel VM, Henriksen SJ (1998) Electrophysio- 
logical characterization of GABAergic neurons in the ventral tegmental area. J Neurosci 18:8003-8015. Medline

Steffensen SC, Taylor SR, Horton ML, Barber EN, Lyle LT, Stobbs SH, Allison DW (2008) Cocaine disinhibits dopamine neurons in the ventral tegmental area via use-dependent blockade of GABA neuron voltage-sensitive sodium channels. Eur J Neurosci 28:2028-2040. CrossRef Medline

Swanson LW (1982) The projections of the ventral tegmental area and adjacent regions: a combined fluorescent retrograde tracer and immunofluorescence study in the rat. Brain Res Bull 9:321-353. CrossRef Medline

Tan KR, Yvon C, Turiault M, Mirzabekov JJ, Doehner J, Labouèbe G, Deisseroth K, Tye KM, Lüscher C (2012) GABA neurons of the VTA drive conditioned place aversion. Neuron 73:1173-1183. CrossRef Medline

Tanda G, Pontieri FE, Frau R, Di Chiara G (1997) Contribution of blockade of the noradrenaline carrier to the increase of extracellular dopamine in the rat prefrontal cortex by amphetamine and cocaine. Eur J Neurosci 9:2077-2085. CrossRef Medline

Ungless MA, Magill PJ, Bolam JP (2004) Uniform inhibition of dopamine neurons in the ventral tegmental area by aversive stimuli. Science 303: 2040-2042. CrossRef Medline

van Zessen R, Phillips JL, Budygin EA, Stuber GD (2012) Activation of VTA GABA neurons disrupts reward consumption. Neuron 73:1184-1194. CrossRef Medline
Wee S, Specio SE, Koob GF (2007) Effects of dose and session duration on cocaine self-administration in rats. J Pharmacol Exp Ther 320:11341143. CrossRef Medline

Yamaguchi T, Sheen W, Morales M (2007) Glutamatergic neurons are present in the rat ventral tegmental area. Eur J Neurosci 25:106-118. CrossRef Medline

Yamaguchi T, Wang HL, Li X, Ng TH, Morales M (2011) Mesocorticolimbic glutamatergic pathway. J Neurosci 31:8476-8490. CrossRef Medline

Zhou Y, Bunney BS, Shi WX (2006) Differential effects of cocaine on firing rate and pattern of dopamine neurons: Role of alphal receptors and comparison with 1-dopa and apomorphine. J Pharmacol Exp Ther 317:196201. Medline

Zweifel LS, Argilli E, Bonci A, Palmiter RD (2008) Role of NMDA receptors in dopamine neurons for plasticity and addictive behaviors. Neuron 59: 486-496. CrossRef Medline

Zweifel LS, Parker JG, Lobb CJ, Rainwater A, Wall VZ, Fadok JP, Darvas M, Kim MJ, Mizumori SJ, Paladini CA, Phillips PE, Palmiter RD (2009) Disruption of NMDAR-dependent burst firing by dopamine neurons provides selective assessment of phasic dopamine-dependent behavior. Proc Natl Acad Sci U S A 106:7281-7288. CrossRef Medline 